\title{
Trend and variability in ozone in the tropical lower stratosphere over 2.5 solar cycles observed by SAGE II and OSIRIS
}

\author{
C. E. Sioris ${ }^{1}$, C. A. McLinden ${ }^{2}$, V. E. Fioletov ${ }^{2}$, C. Adams ${ }^{1}$, J. M. Zawodny ${ }^{3}$, A. E. Bourassa ${ }^{1}$, C. Z. Roth ${ }^{1}$, and \\ D. A. Degenstein ${ }^{1}$ \\ ${ }^{1}$ Institute of Space and Atmospheric Studies, University of Saskatchewan, Saskatoon, Saskatchewan, Canada \\ ${ }^{2}$ Environment Canada, Toronto, Ontario, Canada \\ ${ }^{3}$ NASA Langley Research Center, Hampton, Virginia, USA
}

Correspondence to: C. E. Sioris (csioris@cfa.harvard.edu)

Received: 10 May 2013 - Published in Atmos. Chem. Phys. Discuss.: 21 June 2013

Revised: 20 February 2014 - Accepted: 24 February 2014 - Published: 7 April 2014

\begin{abstract}
We have extended the satellite-based ozone anomaly time series to the present (December 2012) by merging SAGE II (Stratospheric Aerosol and Gas Experiment II) with OSIRIS (Optical Spectrograph and Infrared Imager System) and correcting for the small bias $(\sim 0.5 \%)$ between them, determined using their temporal overlap of 4 years. Analysis of the merged data set (19842012) shows a statistically significant negative trend at all altitudes in the $18-25 \mathrm{~km}$ range, including a trend of $(-4.6 \pm 2.6) \%$ decade $^{-1}$ at $19.5 \mathrm{~km}$ where the relative standard error is a minimum. We are also able to replicate previously reported decadal trends in the tropical lowerstratospheric ozone anomaly based on SAGE II observations. Uncertainties are smaller on the merged trend than the SAGE II trend at all altitudes. Underlying strong fluctuations in ozone anomaly due to El Niño-Southern Oscillation (ENSO), the altitude-dependent quasi-biennial oscillation, and tropopause pressure need to be taken into account to reduce trend uncertainties and, in the case of ENSO, to accurately determine the linear trend just above the tropopause. We also compare the observed ozone trend with a calculated trend that uses information on tropical upwelling and its temporal trend from model simulations, tropopause pressure trend information derived from reanalysis data, and vertical profiles from SAGE II and OSIRIS to determine the vertical gradient of ozone and its trend. We show that the observed trend agrees with the calculated trend and that the magnitude of the calculated trend is dominated by increased tropical upwelling, with minor but increasing contribution from the vertical ozone gradient trend as the tropical tropopause is ap-
\end{abstract}

proached. Improvements are suggested for future regression modelling efforts which could reduce trend uncertainties and biases in trend magnitudes, thereby allowing accurate trend detection to extend below $18 \mathrm{~km}$.

\section{Introduction}

Trends in ozone have been studied for decades. The study of ozone trends became increasingly important as the concentration of ozone-destroying chlorine grew in the stratosphere as a result of anthropogenic emissions of chlorofluorocarbons. The first of a series of assessments of stratospheric ozone, sponsored by the World Meteorological Organization, began in 1981 (WMO, 1982). Trends in the vertical distribution derived from satellite remote sensing observations have been investigated since the 1988 report (WMO, 1990) but were preceded by observed trends for the middle and upper stratosphere from the ground-based Umkehr technique (e.g. Reinsel et al., 1984). The first satellite instruments used for vertically resolved trend analysis were the Stratospheric Aerosol and Gas Experiment (SAGE) I and SBUV (Solar Backscatter Ultraviolet) instruments, although both were limited to the middle and upper stratosphere (altitudes $>25 \mathrm{~km}$ ). Improved analyses of SAGE I and SBUV data have pushed their respective lower limits to an altitude of $20 \mathrm{~km}$. Their successors (SAGE-II and SBUV-II) were launched in 1984. The SAGE instruments, relying on the solar occultation technique, have been accepted as the standard 
among satellite instruments for reliable ozone trend detection since 1988 (WMO, 1990).

Limb-scattering (L-S) satellite-borne sensors provide the ability to study trends in the vertical profile with high vertical resolution and a higher measurement frequency than solar occultation. The Solar Mesosphere Explorer was the first L-S instrument used to study ozone trends (WMO, 1990; Rusch and Clancy, 1988), specifically at the stratopause. Since then, ozone in the $35-45 \mathrm{~km}$ range retrieved from SCIAMACHY (Scanning Imaging Absorption Spectrometer for Atmospheric Chartography; Bovensmann et al., 1999) L-S observations was used in the most recent assessment (WMO, 2011), although only merged with older data sets such as SAGE I and II to provide a sufficiently long combined time series at low and mid-latitudes. OSIRIS (Optical Spectrograph and Infrared Imager System) data were also first used in the 2010 assessment in combination with data from other satellite instruments (including SAGE I, SAGE II, and SCIAMACHY L-S) to determine mid-latitude trends in the $35-45 \mathrm{~km}$ and $20-25 \mathrm{~km}$ ranges in the ozone recovery period 1997-2008 (see also Jones et al., 2009).

The contribution of two high-vertical-resolution satellite instruments, namely HALOE (Halogen Occultation Experiment) and SAGE II, has been considered down to the 13$16 \mathrm{~km}$ range at mid-latitudes (WMO, 2007) and down to the tropopause globally (for SAGE II only) (WMO, 2003). However, very little discussion of tropical trends from satellites in the $17-20 \mathrm{~km}$ range appears in any recent assessment since the realization that SAGE I ozone could not be extended below $20 \mathrm{~km}$ (WMO, 1999). Trends in the tropical lower stratosphere are of interest given modelled changes in the BrewerDobson circulation (e.g. Bunzel and Schmidt, 2013), and with the significant negative trend observed in this region over the last quarter century using a combination of SAGE II and ozonesonde data (Randel and Thompson, 2011).

In this paper, we merge ozone data from SAGE II and OSIRIS to form a 28-year-long anomaly time series and examine variability and updated trends of ozone down near the tropical tropopause $(18 \mathrm{~km})$. It is crucial to understand and accurately quantify other sources of variability to improve trend detection capability. The trend is often secondary in amplitude to stronger signals, e.g. the quasi-biennial oscillation (QBO) and El Niño-Southern Oscillation (ENSO). The longest cyclic phenomenon considered is the 11-year solar cycle; however equivalent effective stratospheric chlorine (EESC) (Newman et al., 2007) has had only one maximum and is currently down $20 \%$ from the peak values of the late 1990s. The explanatory variables are described in Sect. 2.2.

\section{Methods}

In this section, we describe the statistical model used and its inputs, namely the dependent and independent variables (see Sects. 2.1 and 2.2, respectively). The dependent variable is the observed ozone anomaly $\left(\mathrm{dO}_{3}\right.$, described in Sect. 2.1.3). We use a multiple linear regression with no weighting of the observational data (i.e. standard least squares), as is commonly used (e.g. Randel and Thompson, 2011) in this field of research. The regression model can vary as a function of altitude, similar to the work of Hollandsworth and Flynn (WMO, 1998). Here, however, model terms are ultimately dropped at altitudes where they are not statistically significant (defined below). Kirgis et al. (2013) also followed a similar approach with different final regression models developed for different ground-based stations. This tailoring of regression models allows the proportion of explained variance to be meaningful.

\subsection{Dependent variable}

\subsubsection{SAGE II}

The Stratospheric Aerosol and Gas Experiment (SAGE) II measures transmittance during solar occultations in several bands centred at 385, 448, 453, 525, 600, 940, and $1020 \mathrm{~nm}$ (Chu et al., 1989). SAGE II v7.0 ozone profile data (available at https: //eosweb.larc.nasa.gov/cgi-bin/searchTool.cgi?Dataset= SAGE2_AEROSOL_O3_NO2_H2O_BINARY_V7.0) cover the time period of November 1984 to August 2005 and extend from the surface to the lower mesosphere with a vertical resolution of $1 \mathrm{~km}$. Data filtering according to the Wang et al. (2002) recommendation is applied to the entire time series and is effective at removing ozone measurements with large uncertainties or significant aerosol-extinction contamination, such as in the post-Pinatubo period. Clouds at or above the tropical tropopause will be filtered effectively from SAGE II ozone, and SAGE II is not sensitive to clouds below the field of view (FOV) because it uses the solar occultation technique. Additionally, the SAGE II data are filtered with the beta angle criteria from Hassler et al. (2008). The quality of the SAGE II data with respect to detecting temporal trends was discussed in the Introduction. Furthermore, relative to version 6.2, the improved quality of the version 7.0 SAGE II data (Damadeo et al., 2013) was immediately obvious upon switching to the latter as uncertainties were reduced in linear trends at all studied altitudes. Based on the release notes for the version 7.0 SAGE II data, any ozone number density below $35 \mathrm{~km}$ with an uncertainty of $\geq 200 \%$ was filtered out as well as any underlying points in that individual profile.

\subsubsection{OSIRIS}

OSIRIS measures spectra of limb-scattered sunlight from the UV to the near-infrared from onboard the Odin satellite (Llewellyn et al., 2004). Data ranges in time from late 2001 to the present. Thus a valuable extra year of overlap with SAGE II is available compared with the atmospheric 
chemistry instruments on Envisat. The OSIRIS ozone retrieval is described by Degenstein et al. (2009) and retrieved profiles range from cloud top to $60 \mathrm{~km}$ with a vertical resolution of $2 \mathrm{~km}$. Degenstein et al. (2009) showed the version 5 data to be valid to $2 \%$ down to $18 \mathrm{~km}$ by comparisons with SAGE II. The version 5.07 data (available at ftp://odin-osiris.usask.ca/Level2/daily) have been validated most recently and extensively by Adams et al. (2013, 2014). In the tropical upper troposphere, version 5 biases vs. ozonesondes and aircraft observations reach $+5 \%$ (Cooper et al., 2011). Also using OSIRIS ozone from a different retrieval algorithm, Brohede et al. (2007) found a statistically significant +0.045 ppmv year $^{-1}$ drift at $30 \mathrm{~km}$ between 2002 and 2006 at the global scale vs. the submillimetre radiometer (Odin/SMR). Perhaps most relevant to this work, Jones et al. (2009) found no evidence of a $\operatorname{drift}\left(-0.2 \pm 4.4\right.$ and $1.1 \pm 4.9 \%$ decade $^{-1}$ for $20-25 \mathrm{~km}$ and $25-35 \mathrm{~km}$, respectively) versus the average of several instruments (SMR, HALOE, SAGE I, SAGE II, SBUV, SBUV/2, SCIAMACHY) satellite instruments at low latitudes. An earlier version (v2.1) of OSIRIS ozone has been used to validate ozone from other satellite instruments (Dupuy et al., 2009). The role of OSIRIS and other limb-scattering satellite instruments in ozone trend assessment was mentioned in Sect. 1. For OSIRIS, we include only the observations made in the descending node of the orbit to avoid a scattering angle dependence of the retrieved ozone arising from residual aerosol interference that, if neglected, could lead to a trend in ozone as the proportion of ascending and descending node observations has changed over the mission lifetime. The Equator-crossing time in the descending and ascending nodes is $\sim 06: 30 / \sim 18: 30$, respectively (McLinden et al., 2012; Adams et al., 2014) having slightly precessed from 06:00/18:00. (Llewellyn et al., 2004), resulting in no recent equatorial measurements in the ascending node.

Clouds below the FOV can affect the OSIRIS ozone profile at and above the tropical tropopause (Degenstein et al., 2009). Clouds in the FOV are a worst-case scenario, but in the vertical direction, the FOV is only $1 \mathrm{~km}$ at the tangent point (Llewellyn et al., 2004); therefore the tropopause would need to be located above $17.5 \mathrm{~km}$ for tropopause clouds to contaminate ozone data in the $18.0-19.0 \mathrm{~km}$ range (which are reported at $18.5 \mathrm{~km}$ ). However, there are several reasons why clouds should be a minor source of error on the retrieved ozone trend:

1. Clouds would need to have a trend of their own to affect ozone trends. Otherwise, the bias correction between SAGE II and OSIRIS (see Sect. 2.1.3) should largely remove any bias.

2. Bright clouds are rejected (Adams et al., 2013).

3. The solar zenith angles (SZAs) are very large with OSIRIS, particularly in the tropics, which minimizes cloud-related ozone error (Haley et al., 2004).
4. Effective albedo is simultaneously determined during the ozone retrieval and could compensate for the lack of clouds in the forward modelling, particularly for low clouds (Degenstein et al., 2009).

5. The sensitivity of clouds, particularly those at low altitude, is reduced by normalization with a high-altitude reference spectrum (von Savigny et al., 2003). Errors at $20 \mathrm{~km}$ are typically $<1 \%$ when effective albedo is simultaneously retrieved (Flittner et al., 2000).

6. Based on the above arguments, clouds in the FOV are the most likely to have a strong effect; however at the tropical tropopause, they tend to be optically thin.

We also only retain data with SZA of $<89.7^{\circ}$. The leapsecond adjustment between the end of 2005 and the start of 2006 was implemented incorrectly in August 2005, leading to tangent height errors that persisted for three weeks. Therefore, we screen data from 27 August 2005 to 19 September 2005 (inclusive).

\subsubsection{Creation of merged time series}

Zonal monthly means of ozone number density (zmm) are generated in $1 \mathrm{~km}$ altitude bins (e.g. $16.5 \pm 0.5 \mathrm{~km}, \ldots$, $25.5 \pm 0.5 \mathrm{~km}$ ) and in $9^{\circ}$ wide latitude bins. Ozone anomalies are obtained at each latitude and altitude bin, for each instrument using

$d \mathrm{O}_{3}(y, m)=\frac{\mathrm{zmm}(y, m)-\mathrm{zmmc}(m) \times \mathrm{zmo} / \mathrm{zmc}}{(\mathrm{zmo}+\mathrm{zmo} 2) / 2}$,

where $y$ is the year, $m$ is the month, and zmmc is the climatology from one instrument (e.g. SAGE II) over its full data record as a function of month. Averaging zmmc over all months of the year yields the climatological mean zmc; zmo and zmo2 are the respective means over all months in the overlap period for that instrument and the other (e.g. OSIRIS). The denominator in Eq. (1) represents the intersensor mean ozone in the overlap period. Equation (1) indicates that the monthly ozone anomaly time series from each instrument is deseasonalized with its own climatology. This was necessary since there were slight differences in the seasonal cycle between SAGE II and OSIRIS just above the tropopause (particularly at $19.5 \mathrm{~km}$ ), where SAGE II peaks in September, in agreement with HALOE (Konopka et al., 2010), whereas OSIRIS peaks in July. Sensor-specific deseasonalization has been used previously (Randel and Thompson, 2011; Jones et al., 2009). However, since the climatologies for the two instruments cover different periods and a temporal trend may exist, we scale the climatology to make it appropriate for the overlap period by multiplying by the ratio in the numerator. This step is necessary to correctly determine any bias between the ozone anomalies of the two instruments in the overlap period (see below). The denominator normalizes the differences in the numerator to yield the 
relative quantity known as the ozone anomaly. Some seasonality may appear to remain in the ozone anomaly time series if the zonal monthly means have a distribution about their monthly climatological mean that is skewed.

The latitude bin centred at the Equator was selected for trend analysis since the focus of the paper is the tropical pipe where negative trends have been observed to be largest just above the tropical tropopause (Forster et al., 2007). As a test, we widened the latitude bin from $5^{\circ}\left(2.5^{\circ} \mathrm{N}-\right.$ $\left.2.5^{\circ} \mathrm{S}\right)$ to $15^{\circ}\left(7.5^{\circ} \mathrm{N}-7.5^{\circ} \mathrm{S}\right)$ and observed a slight reduction $\left(0.5 \%\right.$ decade $\left.^{-1}\right)$ in the magnitude of the linear trend but essentially the same shape in the vertical profile of the trend. Latitude bin sizes of $4,6,10,12$, and 18 were also tested in terms of the uncertainty on the linear trend and the anomaly bias. For latitude bands wider than $9^{\circ}$, the trend uncertainty tends to grow, presumably due to the larger proportion of unexplained variance resulting from spatial heterogeneity of ozone as well as opposite phases of seasonal cycles to the north and south of the Equator. For latitude bands that are too narrow, the small monthly sample sizes, particularly for SAGE II, lead to larger linear trend uncertainties, as well as scatter in the altitude dependence in the anomaly bias between SAGE II and OSIRIS in the overlap period at the lowest altitudes, where a large fraction of the SAGE II data are filtered.

The number of years for which a calendar month is populated must be $>5$ for each instrument in order that the climatology and resulting ozone anomalies for that calendar month are not noisy and are representative of the full merged data record. A minimum of 10 individual ozone profile measurements in the latitude and altitude bin of interest must be available per month for the month to be included in the analysed time series. During the overlap period (2001-2005), the number of measurements from the two sensors is not summed. If only one sensor has $\geq 10$ measurements in a given month and altitude, then only data from that sensor are retained in the merged data record. If both sensors have $\geq 10$ measurements in a given month and altitude, then the inter-sensor monthly mean is used. During the overlap period, for months where both instruments have sufficient data, biases between SAGE II and OSIRIS ozone anomalies are small $(<1 \%)$ but show an altitude dependence (Fig. 1). Thus, at each altitude, there must also be more than two months during the overlap period for which both sensors measured ozone in order for the intersensor anomaly bias to be adequately corrected. This bias (averaged over the overlap period) is used to adjust the entire OSIRIS anomaly time series. At $15.5 \mathrm{~km}$, there is only one month with sufficient SAGE II data, and so the lower limit is set at $16.5 \mathrm{~km}$. However, at $16.5 \mathrm{~km}$, there are only three months (August-October) in the full SAGE II data record with sufficient data in the latitude bin of interest $\left(0 \pm 4.5^{\circ}\right)$, and thus it is difficult to assess the seasonality of the data. The situation improves at higher altitudes, where at 17.5, 18.5 , and $20.5 \mathrm{~km}$, and at or above $21.5 \mathrm{~km}$, the number of sampled calendar months during the full SAGE II mission in-

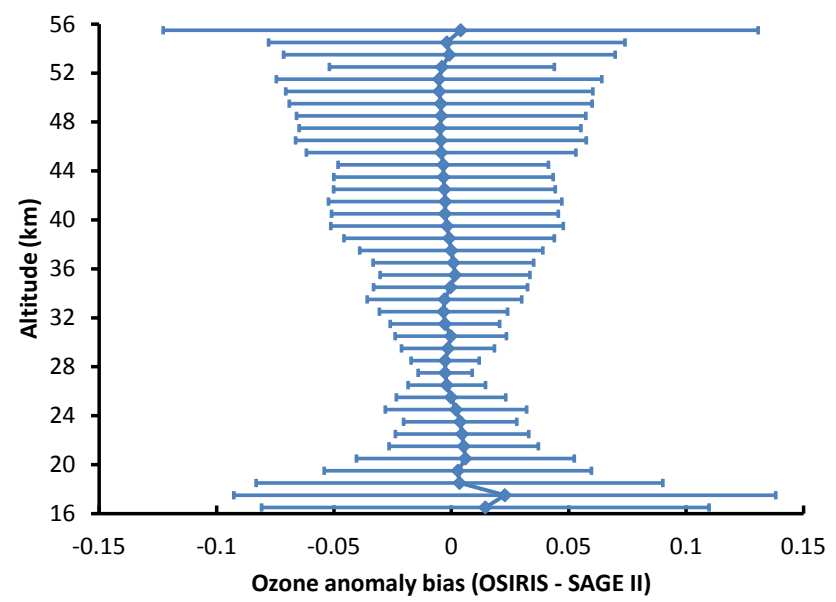

Fig. 1. Anomaly bias between the two sensors at the Equator $\left( \pm 4.5^{\circ}\right.$ latitude) determined from averaging monthly ozone anomalies in the overlap period (2001-2005). The mean bias is $0.00 \pm 0.005(1 \sigma)$ over the 16 to $56 \mathrm{~km}$ range. The error bar represents the standard deviation of the anomaly differences in the overlap period and reflects the seasonal variability of the anomaly bias in the lower stratosphere.

creases to $7,9,10$, and 11 , respectively. Given that a seasonal trend would be considered as a basis function (discussed below), we opted not to include $16.5 \mathrm{~km}$ since only one season was sampled. December is never sampled by SAGE II in this latitude bin at any altitude $(15.5-25.5 \mathrm{~km})$. Thus, the lowest altitude for regression modelling is $17.5 \mathrm{~km}$.

In practice, zmo and zmo2 are calculated only for months when both instruments provided an ozone anomaly to avoid a temporal sampling bias with SAGE II. Just above the tropopause, the anomaly biases change from being positive (for OSIRIS relative to SAGE II) in spring to negative in the autumn. The use of monthly means in this work paints a different picture of the bias as compared with pairwise coincidences (Adams et al., 2013), which are unevenly spread over the year. Furthermore, the deseasonalization reduces the magnitude of the seasonally dependent biases and averaging over the overlap period largely cancels out the seasonally alternating anomaly biases.

The upper altitude in this study is the lowest stratospheric altitude for which the linear trend is statistically insignificant $(25.5 \mathrm{~km})$.

\subsection{Independent variables}

Currently, there is no consensus within the community on which predictor variables to use. The altitude and latitude ranges of interest play a role in determining which predictor variables should be tested. Here we introduce several predictor variables that are either used only in testing or are included in the final regression model. 


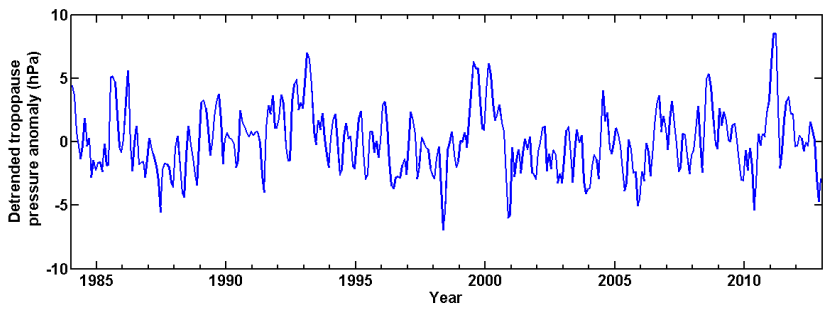

Fig. 2. Deseasonalized and detrended tropopause pressure time series in the January 1984 to December 2012 time frame. The mean tropopause pressure is $103.3 \mathrm{hPa}$, with a $95 \% \mathrm{CI}$ of $\pm 0.3 \mathrm{hPa}$ (uncertainties hereafter are $95 \%$ CI unless noted otherwise). There is a temporal trend towards a lower tropopause pressure (higher tropopause height): $-2.9( \pm 0.9) \mathrm{hPa}$ over 29 years, consistent with a previous estimate of tropopause height trend (1980-2004) based on simulations (Lamarque and Solomon, 2010). The standard deviation of $\mathrm{d} p_{\text {trop }}$ is $2.5 \mathrm{hPa}$ and represents the magnitude of a typical anomaly shown above.

The linear term represents the sum of all processes that produce a linear ozone response, plus any process whose ozone response has a linear component. The most likely physical process contributing to the linear response in ozone is the increase in atmospheric carbon dioxide (Lamarque and Solomon, 2010), which also determines the trend in tropopause pressure (see caption of Fig. 2) and sea surface temperature on decadal timescales. Using monthly insitu measurements from Mauna Loa (http://www.esrl.noaa. gov/gmd/ccgg/data.html), the growth in atmospheric $\mathrm{CO}_{2}$ is well approximated by the linear term (correlation coefficient $r=0.996)$ over the merged data record. The indirect relationship between linear trends in $\mathrm{CO}_{2}$ and tropical lowerstratospheric ozone will be elucidated below (Sect. 4.1). For simplicity and to avoid stronger correlation with EESC, a higher-order polynomial was not used in regression modelling of ozone anomalies. A quadratic was tested at $17.5 \mathrm{~km}$ and was not statistically significant (whereas EESC is a statistically significant term). The seasonal variation of a linear trend can also be included (e.g. Randel and Wu, 2007). The seasonal trend terms can be useful in accounting for residual seasonality due to differences in the phase of the observed seasonal cycle between the two instruments.

ENSO affects tropical upwelling, which in turn leads to fluctuations in temperature and ozone in the tropical lower stratosphere (Randel et al., 2009, and references therein). ENSO variability is based on the multivariate ENSO index (MEI) obtained from the NOAA Climate Diagnostics Center (Wolter, 2013). The ENSO signal in the upper troposphere lags behind the one at the surface, and the stratospheric signal lags further behind according to the age of air.

In the tropical lower stratosphere, at the time when the vertical derivative of the zonal wind is a maximum, there is maximal diabatic cooling, which induces sinking of air parcels through isentropic surfaces (Baldwin et al., 2001), transporting higher ozone mixing ratios downward. These maxima occur quasi-biennially, exhibiting a downward propagation from the middle to lower stratosphere. QBO time series are available at seven pressures $(70,50,40,30,20$, 15 , and $10 \mathrm{hPa}$ ) http://www.geo.fu-berlin.de/en/met/ag/strat/ produkte/qbo/index.html (Naujokat, 1986) and from this set of time series, two orthogonal ones are also generated (Randel and $\mathrm{Wu}, 2007)$, named QBOa and QBOb hereafter. Because the QBO signal has an altitude-dependent lag and the number of available QBO pressures is insufficient for instruments with high vertical resolution and sampling (such as OSIRIS and SAGE II), one of two solutions is generally used, either of which uses two fitted quantities. Either a single QBO proxy is fitted along with a fitted lag to make the phase appropriate for the ozone response at the local altitude, or two QBO basis functions are fitted that tend to naturally account for the difference between the local phase and the phases at the pressures of the two QBO time series. In the latter approach, the two basis functions tend to be orthogonal or tend to envelop the local pressure. In this work, the use of two QBO basis functions is preferred over the approach of using a lag, particularly because of the strong altitude dependence of the QBO signature (in addition to the altitude-dependent lag) in the lower stratosphere (discussed in Sect. 3.3). There is strong correlation $(r>0.5)$ between any pair of adjacent QBO pressures. For the QBO time series at 10 and $15 \mathrm{hPa}$, there is strong anti-correlation with each of the QBO time series at 50 and $70 \mathrm{hPa}$ (i.e. opposite phase). For the QBO time series at $70 \mathrm{hPa}$, there is also strong anti-correlation with the QBO time series at $20 \mathrm{hPa}$. Correlation coefficients are $<0.5$ for all other pairs.

Hood et al. (2010) review the various physical mechanisms that could lead to a lower-stratospheric ozone response to solar cycle variations. The solar cycle proxy is the $10.7 \mathrm{~cm}$ radio flux, obtained from ftp://ftp.ngdc. noaa.gov/STP/space-weather/solar-data/solar-features/ solar-radio/noontime-flux/penticton/penticton_adjusted/ listings/listing_drao_noontime-flux-adjusted_daily.txt

Total ozone is well known to be correlated with tropopause pressure, even over large spatial scales, particularly near $30^{\circ} \mathrm{S}$ in austral summer, whereas at the Equator, the correlation is much weaker (Schubert and Munteanu, 1988). Stratospheric ozone mixing ratio also has been shown to correlate with tropopause height at southern mid-latitudes (Bodeker et al., 1998). For tropopause pressure, we use the zonal monthly mean from NCEP (National Centers for Environmental Prediction) reanalysis (Kalnay et al., 1996, ftp://ftp.cdc. noaa.gov/Datasets/ncep.reanalysis.derived/tropopause/). The tropopause pressure is averaged over the three NCEP latitude grid points contained in our -4.5 to $4.5^{\circ}$ latitude band. After removing its strong seasonal cycle and weak linear trend, we obtain $\mathrm{d} p_{\text {trop }}$ (Fig. 2). A slight correlation was found between $\mathrm{d} p_{\text {trop }}$ and aerosol extinction (see below) at $18.5 \mathrm{~km}$ $(r=0.3)$, with QBOa $(r=0.3)$, and a slight anti-correlation $(r=-0.2)$ with ENSO (with no lag). 
The EESC octic has the following coefficients:

$$
\begin{aligned}
& \operatorname{EESC}(t)=0.1809734+0.71710218 \mathrm{~d} t \\
& \quad+0.14525718 \mathrm{~d} t^{2}-0.03355533 \mathrm{~d} t^{3} \\
& \quad+0.0040246245 \mathrm{~d} t^{4}-2.567041 \times 10^{-4} \mathrm{~d} t^{5} \\
& \quad+8.5901032 \times 10^{-6} \mathrm{~d} t^{6} \\
& \quad-1.434144 \times 10^{-7} \mathrm{~d} t^{7}+9.451393 \times 10^{-10} \mathrm{~d} t^{8},
\end{aligned}
$$

where $\mathrm{d} t=t-1979$ (updated version of top panel of Fig. 13 of Fioletov, 2008), and $t$ is the time in decimal years. It peaks in early 1999 (corresponding to a mean age of air of 3 years) and is expected to be valid until $\sim 2015$. EESC is not adjusted for any variation in the age of air with height in the tropical lower stratosphere since it is possible, given the model results by Lamarque and Solomon (2010) and regression fits of observed ozone by Bodeker et al. (2013), that EESC actually has a slightly positive overall response in the tropical lower stratosphere by destroying ozone in the upper stratosphere which stimulates production below, and thus the age of air in the upper stratosphere would be more relevant.

Our starting premise is that the simplest model of the timedependent ozone anomaly which could be accurate for trends throughout the tropical lower stratosphere is the following:

$$
\begin{aligned}
d \mathrm{O}_{3}(t) & =c_{1}(t-\bar{t})+c_{\mathrm{ENSO}} \operatorname{ENSO}(t-L(z)) \\
& +\sum_{n=1}^{2} c_{\mathrm{QBO} n} \mathrm{QBO}_{n}(t)+c_{\mathrm{Sol}} \operatorname{Sol}(t)+c,
\end{aligned}
$$

where the linear trend term contains the fitting coefficient $c_{1}$, and represents the trend over the 28-year period with $\bar{t}=1998.5$ being the midpoint of the time series. The ENSO term includes the altitude-dependent lag, $L(z)$, which is set to 1 month for the tests below, appropriate for the lowest stratospheric altitudes where the sensitivity to ENSO is greatest. The QBO is modelled with two nearly orthogonal terms (30 and $70 \mathrm{hPa}$ for testing). The QBO and the solar cycle (sol) are included in the regression model following convention (e.g. WMO, 1998). Equation (3) is similar to the regression model used by Randel and Thompson (2011) except that it excludes annual harmonics of predictors but includes a constant $(c)$ since our merged ozone anomaly does not average over time to zero. Note that the mean is removed from all independent variables. This "simplest accurate model" is based on evidence from trend-sensitivity tests at $17.5 \mathrm{~km}$ that show that a regression model without ENSO does not agree with respect to the linear trend with the trend from a model including ENSO, possibly partly due to the gaps in the SAGE II data record in the aftermath of the El Chichón and Pinatubo eruptions and the strong La Niña events that followed $\sim 7$ years after each (shown and discussed below in Sect. 3). Annual harmonics of QBO, ENSO, and solar and linear terms were not included for testing because the seasonal cycle differences between the instruments in the $17.5-20.5 \mathrm{~km}$ range im- plied that the merged data record was not suitable for the determination of these harmonic signals in this altitude range.

Given this simple regression model as a starting point, we examined the bias and uncertainty of the linear trend upon the stepwise inclusion of additional basis functions in order to decide whether these basis functions were suitable. Candidate predictors were tested in the following order:

1. annual cycle (sine and cosine harmonics),

2. tropopause pressure,

3. EESC.

We found that the inclusion of the annual cycle does not improve the linear trend uncertainties and thus it was also not considered further as a basis function. This is encouraging since it indicates that there is not much residual seasonality left in the merged (deseasonalized) ozone anomaly time series. Given that the annual cycle is excluded, we tested the inclusion of tropopause pressure to the model in Eq. (3) and found that it improves trend uncertainties at all altitudes, but particularly in the lowest three levels (17.5$19.5 \mathrm{~km}$ ) and does not have a statistically significant effect on the magnitude of the linear trend vertical profile. As a result, tropopause pressure is considered in the next stage of optimized regression modelling (described below). Subsequently, we tested the inclusion of EESC into a model already including tropopause pressure and the other terms on the right-hand side of Eq. (3). We find that EESC has a slight (statistically insignificant) impact on the magnitude of the linear trend, and only improves the linear trend uncertainty at 17.5 and $18.5 \mathrm{~km}$. Thus, we keep EESC as a predictor variable only below $19 \mathrm{~km}$ in order to improve the uncertainty on the linear trend there as well as to obtain a slightly less biased linear trend estimate assuming that the EESC signature there is real. The EESC signal near the tropical tropopause is believed to be real since the ozone response is positive and grows with decreasing altitude, in agreement with coupled chemistry-climate model simulations (Lamarque and Solomon, 2010). EESC is different from an oscillatory proxy time series such as the annual cycle, since the latter should have no trend-biasing tendency with its short period and long-term average of 0 .

Aerosol extinction is measured by both SAGE II and OSIRIS (Bourassa et al. , 2012, and references therein) and may help predict ozone considering the role of aerosols in determining photolytic fluxes. However, the trend in aerosol extinction even in unperturbed conditions can affect the fitted magnitude of the linear trend in ozone (Solomon et al., 2012). The fitting coefficient for an aerosol extinction basis function might be driven by short-term variations in the ozone response (e.g. arising from ozone retrieval artefacts following volcanic eruptions), whereas the long-term correlation between ozone to aerosol extinction may reflect some combination of atmospheric processes. If so, the long-term 
ozone response to aerosol extinction may be of the opposite sign to the short-term response and thus the long-term trend in aerosol extinction could bias the determination of the linear trend in ozone. As a result, we omit aerosol extinction as a candidate basis function, particularly since both SAGE II transmittances and OSIRIS radiances are sensitive to aerosol extinction owing to their wavelength ranges, and consequently their respective ozone retrievals can be adversely affected (Wang et al., 2002; Adams et al., 2013).

Also not considered further for regression modelling with the merged data record is the seasonal trend. This decision is based on the fact that the seasonal trend was not a statistically significant term based on regression model tests using only SAGE II data above $17 \mathrm{~km}$. Testing with SAGE II alone ensures that the seasonal trend is not simply serving to account for ozone seasonality differences between the two instruments. A test using the merged data record and the model in Eq. (3) plus the annual cycle term indicate that the inclusion of a seasonal trend did not improve the linear trend uncertainty consistently versus altitude, supporting its exclusion from subsequent regression modelling in this study.

Above $21 \mathrm{~km}$, the instruments are in phase with each other in terms of the seasonal cycle of ozone number density with the maximum in May between 21.5 and $24.5 \mathrm{~km}$ and correlations coefficients of $0.77-0.92$ for their monthly climatologies in the $21.5-25.5 \mathrm{~km}$ range. For these altitudes, we consider seasonality of the following predictors in the final regression model: QBO, ENSO, and solar, with the highest frequency being semi-annual since there is an apparent semi-annual signal in both the OSIRIS and SAGE II climatologies as low as 23.5 and $24.5 \mathrm{~km}$, respectively, with the difference possibly related to the difference in vertical resolution of the instruments or monthly sampling issues in the SAGE II time series. Similarly, the semi-annual oscillation (SAO) is detectable in UARS/MLS $\mathrm{O}_{3}$ starting at $30 \mathrm{mb}$ $(24 \mathrm{~km})$ (Ray et al., 1994) with all three sensors in agreement on its phase. Thus we also consider the SAO. We again perform linear trend sensitivity studies with respect to the change in its uncertainty and bias after including harmonics. For this round of tests, we study only the relevant altitude range (21.5-25.5 km) and thus use a more appropriate ENSO lag of 3 months (Hood et al., 2010) and the orthogonalized QBO time series (Randel and $\mathrm{Wu}, 2007)$. The starting model is thus

$$
\begin{aligned}
& d \mathrm{O}_{3}(t)=c_{1}(t-\bar{t})+c_{\mathrm{ENSO}} \operatorname{ENSO}(t-L(z)) \\
& \quad+\sum_{n=1}^{2} c_{\mathrm{QBO} n} \mathrm{QBO} n(t)+c_{\mathrm{sol}} \operatorname{sol}(t)+c_{\mathrm{d} p_{\text {trop }}} \mathrm{d} p_{\text {trop }}(t)+c
\end{aligned}
$$

and candidate harmonics are tested in the following order:

1. QBO annual,

2. ENSO annual,

3. solar annual,
4. (constant) semi-annual,

5. QBO semi-annual.

Based on this sequence of tests, we retain QBO annual harmonics and exclude ENSO and solar annual harmonics. Semi-annual harmonics of solar and ENSO terms as well as the semi-annual variation of the linear trend were skipped since their annual counterparts were excluded. The inclusion of a semi-annual cycle did not improve the trend uncertainty, particularly between 23.5 and $25.5 \mathrm{~km}$, where some improvement might be expected if it were a useful predictor, and so it was also excluded. However, the QBO semi-annual cycle uniformly improved trend uncertainties without inducing any linear trend bias, and so it was retained. We note that Ray et al. (1994) also found interannual temperature variability in the semi-annual cycle and partly attributed it to the QBO, albeit on a very short data record. Wallace et al. (1993) found that the semi-annual cycle in the QBO has comparable statistical significance to the annual cycle, even though they included pressures as low as $10 \mathrm{mb}$.

We use a bidirectional stepwise elimination procedure to determine a final regression model at each altitude including each predictor which has the following criteria:

1. reduces the linear trend uncertainty relative a model without this predictor,

2. does not result in a statistically significant change in the magnitude of the linear trend relative a model without this predictor,

3. has a fitting coefficient whose magnitude is greater than its $95 \%$ confidence interval (CI).

Criterion 2 is required to avoid the inclusion of trended predictors whose power is mostly at short periods, since such predictors could lead to an incorrect determination of the long-term trend in ozone. This possibility is discussed above with respect to aerosol extinction. Further details on each predictor are presented here in the order in which they were introduced above, starting with Eq. (3). These details pertain to the final regression modelling stage, in which the altitude dependence of certain predictors is considered (e.g. ENSO lag, QBO) and statistically insignificant terms are excluded from the final trend model at each altitude.

Regarding ENSO, the tropical tropopause region may take half a month or more to respond to tropical sea surface temperature anomalies, and larger lags are expected for the stratosphere. We derive the ENSO lag using increments of 0.5 months. Half-month lags are calculated by averaging time series lagged by consecutive integer months. To avoid finding a lag that leads to a local but not a global minimum in linear trend uncertainty, the lag is incremented month by month for all lags smaller than the first local minimum found and then half-month lags were used to fine-tune the lag near 
the integer-month lag providing the smallest linear trend uncertainty. The lag first guess is the fitted lag from the immediately underlying altitude. The first-guess lag at the lowest altitude $(17.5 \mathrm{~km})$ is 0 months. After adjusting the lag, the stepwise elimination procedure is repeated using the criteria listed above. The ENSO altitude-dependent lag has been determined using SBUV(/2) ozone time series by Hood et al. (2010). ENSO harmonics have been used previously when fitting ozone time series (Bodeker et al., 1998; Randel and Thompson, 2011). However, based on tests described above, ENSO harmonics are not included here.

Regarding modelling of the QBO signal, the first step is to find which of the QBO time series (i.e. pressure) leads to a minimum in the linear trend uncertainty while meeting the three criteria listed above. Following this, the best complementary pressure is sought to pair with this best single QBO pressure. The use of this pair of QBO time series is then compared with the best pair from the altitude below (if available) and the pair of orthogonalized QBO basis functions (Randel and $\mathrm{Wu}, 2007$ ) in terms of which provides the smallest linear trend uncertainty.

Regarding EESC, Bodeker et al. (2013) also fitted it simultaneously with the linear term. Annual harmonics were not attempted for EESC since EESC (Bodeker et al., 2013) does not exhibit a strong seasonal cycle in the equatorial lower stratosphere and reactive inorganic chlorine is absent.

Solar harmonics were not considered based on the above tests, similar to Bodeker et al. (1998).

One of the pitfalls of multivariate regression modelling occurs when correlated predictors are used simultaneously. Thus, we examined periodograms of the predictors as well as their correlation matrix for the 1984-2012 time period. For ENSO, the power is largest at slightly $<4$ years but there is a second period of $\sim 6$ years with comparable power. For the QBO, the peak in the periodogram is at slightly longer than 2 years, as expected (Witte et al., 2008). The solar cycle has a single poorly resolved peak with an approximate period of a decade, corresponding to the well-known 11year solar cycle. After deseasonalizing and detrending the tropopause pressure, the most power lies at a period of exactly 6 months, although there are secondary peaks corresponding to the maxima for QBO, ENSO, and the solar cycle of 27 months, $\sim 4$ years, and one decade. The QBO annual harmonics have beat periods of $\sim 8$ and $\sim 20$ months. Finally, the QBO semi-annual harmonics show the expected periods of $1 /(12 / 6 \pm 12 / 27)$, equal to 0.41 and 0.64 years. Strong correlations between certain pairs of QBO basis functions were mentioned above. If the pair of QBO basis functions is approximately orthogonal, their sine (or cosine) harmonics also tend to be orthogonal. Given that the primary periodicities for QBO semi-annual harmonics and deseasonalized tropopause pressure are similar, it is worth noting that the long data record allows their correlation coefficients to be 0.0. The expected, slight correlations of tropopause pressure with QBOa and ENSO were noted above. Apart from the linear trend with EESC, no other correlations are statistically significant (also discussed above).

At $17.5 \mathrm{~km}$, we start with the model in Eq. (3) plus EESC. The final regression model obtained at $17.5 \mathrm{~km}$ serves as a starting model for $18.5 \mathrm{~km}$ and so on, up to $20.5 \mathrm{~km}$. EESC, however, is not considered above $18.5 \mathrm{~km}$ (as discussed above). Above $21 \mathrm{~km}$, the full array of available model terms becomes

$$
\begin{aligned}
d \mathrm{O}_{3}(t)= & c_{1}(t-\bar{t}) \\
& +c_{\mathrm{ENSO}} \operatorname{ENSO}(t-L(z)) \\
& +\sum_{n=1}^{2} c_{\mathrm{aQBO} n} \mathrm{QBO}_{n}(t)+\sum_{n=1}^{2} \sum_{x=1}^{2} \\
& \left(c_{\mathrm{bQBO} n} \cos (x \pi t)+c_{\mathrm{cQBO} n} \sin (x \pi t)\right) \mathrm{QBO}_{n}(t) \\
& +c_{\mathrm{sol}} \operatorname{sol}(t) \\
& +c_{\mathrm{d} p_{\text {trop }}} \mathrm{d} p_{\text {trop }}(t) \\
& +c
\end{aligned}
$$

with 16 fitted parameters including the ENSO lag. At $21.5 \mathrm{~km}$, we start with the final regression model from $20.5 \mathrm{~km}$ and so on, up until the altitude where the linear trend is not different from 0 considering its uncertainty. Note that the constant and linear term are handled differently than all other predictors since the constant is, in general, necessary because the dependent variable does not average over time to zero, but its inclusion can increase the linear trend uncertainty. A constant or linear term is included based only on the third criterion. Also, at $25.5 \mathrm{~km}$, where the linear term is not statistically significant, the inclusion of each model parameter defaults to only the third criterion, and the $r^{2}$ statistic was used to determine the optimal ENSO lag and the best QBO pair. Special attention was paid to linear trend magnitude and uncertainties for regression models with correlated predictor variables (discussed in Sect. 3).

\subsection{Uncertainties including autocorrelation}

The uncertainty margin takes into account the AR1 autocorrelation in the residuals using

$\varepsilon_{c_{1}}^{\prime}=\varepsilon_{c_{1}} \sqrt{\frac{1+\varphi}{1-\varphi}}$,

where $\varepsilon_{c_{1}}^{\prime}$ and $\varepsilon_{c_{1}}$ are the uncertainty on a fitting coefficient with and without accounting for autocorrelation of the residuals, respectively, and $\varphi$ is the autocorrelation between time series shifted by 1 month. The autocorrelation correction of all uncertainties is calculated after the final model is determined at each altitude; that is, it is not calculated prior to that point. 


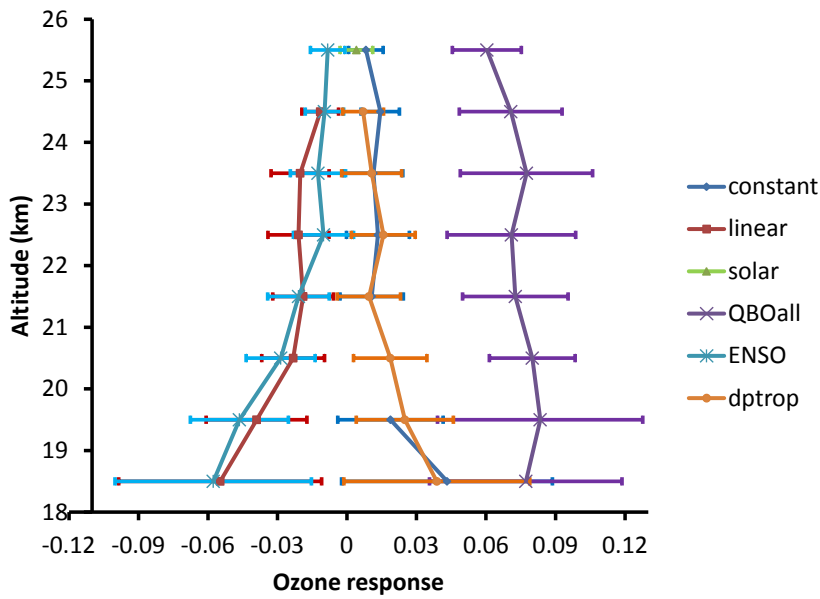

Fig. 3. Ozone response and uncertainty ( $95 \% \mathrm{CI}$, accounting for autocorrelation of the residuals) to various predictors (see Eq. (7) and the text for formula for response and its uncertainty, except for constant, whose response and its uncertainty are the fit coefficient and its $95 \% \mathrm{CI}$ ). The linear response is proportional but not equal to the decadal trend. QBOall is the combined ozone response to all QBO terms (including harmonics).

\section{Results}

In this section, we discuss the ozone anomaly response to the various predictor variables determined by regression modelling. Figure 3 provides the ozone response to various terms included in the "best regression model" at each altitude using the methods described in Sect. 2. Table 1 complements Fig. 3 by providing various statistics and details on the best regression model at each altitude. The ozone response and its uncertainty are calculated as the standard deviation of the basis function multiplied by its fitting coefficient or fitting coefficient $95 \%$ CI, respectively. For the QBO, we combine the ozone response to each associated, retained basis function (including harmonics) in the following generalized form:

$$
\begin{array}{r}
\text { response }_{\mathrm{QBO}}=\mathrm{SD}\left(\sum_{n=1}^{2} c_{\mathrm{aQBO}_{n}} \mathrm{QBO}_{n}(t)+\sum_{n=1}^{2} \sum_{x=1}^{2}\right. \\
\left.\left(c_{\mathrm{bQBO}_{n}} \cos (x \pi t)+c_{\mathrm{cQBO}_{n}} \sin (x \pi t)\right) \mathrm{QBO}_{n}(t)\right),
\end{array}
$$

where "response" is a time-integrated quantity and SD is the standard deviation of all of the monthly points in the time series (e.g. 1984-2012). The overall response to QBO is different from the other responses because it will always result in a positive number when calculated with Eq. (7). The uncertainty in the response to QBO is calculated following Eq. (7), but the fit coefficients are replaced with their respective $95 \%$ CIs.

\subsection{Linear trend}

Using any of the best regression models developed in the 18.5 to $25.5 \mathrm{~km}$ range (Fig. 3, Table 1 ), the linear trend at

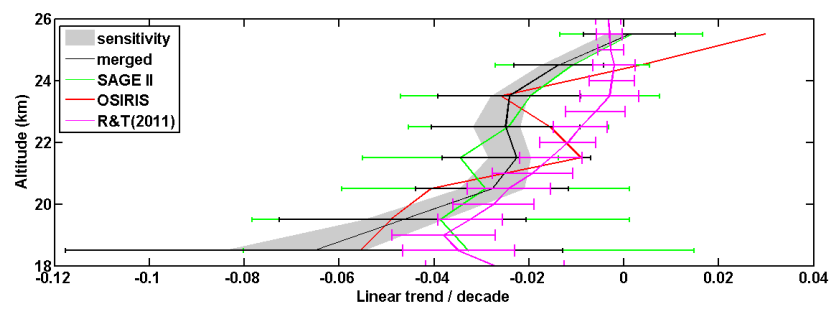

Fig. 4. Decadal trend profile in the $0 \pm 4.5^{\circ}$ latitude band for the merged data set (1984-2012, blue line) using the best regression model at each height. The $95 \% \mathrm{CI}$ is shown as the error bar. At $25.5 \mathrm{~km}$, the best regression model does not include a linear trend term (see Fig. 3). To illustrate that the magnitude of the linear trend becomes statistically insignificant at $25.5 \mathrm{~km}$, the linear trend term was added to the best regression model for $25.5 \mathrm{~km}$. The grey area illustrates the sensitivity of the linear trend vertical profile for the merged data set to the regression model terms, tested by applying best regression models (see Fig. 3 and Table 1) to different altitudes to generate trend profiles. The grey area shows the standard deviation $(1 \sigma)$ about their median trend. Trends from OSIRIS (20012012) with error bars omitted (see text), SAGE II (1984-2005), and Randel and Thompson ("R\&T (2011)") are also shown.

$18.5 \mathrm{~km}$ for the 1984-2012 time frame is always negative and a maximum in magnitude in the $18.5-55.5 \mathrm{~km}$ range (Fig. 4 extends to $25.5 \mathrm{~km}$ ). In fact, using any of these models, the altitudes with the largest trends, listed in order of increasing trend magnitude, are always 19.5 and $18.5 \mathrm{~km}$. This indicates that there is a linear trend in the tropical lower stratosphere strengthening toward the tropopause, seen also in the SAGE II trend. However, at $17.5 \mathrm{~km}$, the magnitude of the trend from the merged data set is too large (not shown), inconsistent with the trends from the individual satellite instruments, even considering the confidence interval of the merged trend. Note that for the trends from the individual satellite data sets, we used the best regression models (Fig. 3, Table 1) and, at $17.5 \mathrm{~km}$, the best regression model includes QBO, tropopause pressure, ENSO, the linear trend, and the constant term, but not EESC, since EESC cannot be applied simultaneously with the linear trend on the individual satellite data sets because of the high correlation of these predictors over shorter timescales.

The large linear trend at $17.5 \mathrm{~km}$ in the merged data set is not related to the inclusion of EESC, since excluding EESC from the model at $17.5 \mathrm{~km}$ does not result in a statistically significant change in the linear trend magnitude. This discrepancy in trends at $17.5 \mathrm{~km}$ likely results from the small sample size of available months of overlap $(N=12)$, relative to $N=24$ at most altitudes. This is mostly due to the sparseness of the SAGE II data set after filtering for aerosol contamination. The large standard deviation of the anomaly bias (Fig. 1), which is largest among all stratospheric altitudes at $17.5 \mathrm{~km}$, may be partly due to the small sample size. Furthermore, including an indicator function (1 for OSIRIS time frame, 0 for pre-OSIRIS time frame) in the best regression 
Table 1. Regression statistics versus altitude. The best single pressure for the QBO in terms of explaining variance is shown in the third column from the right. $K$ is the number of basis functions. In the QBO harmonics column, $c 1, s 1, c 2$, and $s 2$ denote cosine and sine annual and semi-annual harmonics, respectively, and are preceded by the relevant QBO pressure.

\begin{tabular}{rrrrrrrr}
\hline$z(\mathrm{~km})$ & $r^{2}$ & $F$ & $\begin{array}{r}\text { best QBO } p \\
(\mathrm{hPa})\end{array}$ & QBO pair & $\begin{array}{r}\text { QBO } \\
\text { harmonics }\end{array}$ & $\begin{array}{r}\text { ENSO lag } \\
(\mathrm{months})\end{array}$ & $K$ \\
\hline 17.5 & 0.576 & 40.5326 & 70 & 30,70 & $\mathrm{~N} / \mathrm{A}$ & 0.5 & 7 \\
18.5 & 0.6161 & 75.0415 & 70 & N/A & N/A & 1.5 & 5 \\
19.5 & 0.7411 & 107.0079 & 50 & 50,70 & $\mathrm{~N} / \mathrm{A}$ & 1.5 & 6 \\
20.5 & 0.7835 & 172.8777 & 50 & 20,50 & $\mathrm{~N} / \mathrm{A}$ & 1.5 & 5 \\
21.5 & 0.8068 & 114.5697 & 40 & 15,40 & $15: \mathrm{s} 1,40: \mathrm{c} 1$ & 3 & 8 \\
22.5 & 0.8034 & 100.104 & 30 & 10,30 & $10: \mathrm{s} 1, \mathrm{~s} 2, \mathrm{c} 2$ & 1.5 & 9 \\
23.5 & 0.8076 & 104.945 & 20 & 10,30 & $10: \mathrm{c} 1, \mathrm{~s} 2 ; 30: \mathrm{s} 1$ & 9 & 9 \\
24.5 & 0.8364 & 121.5389 & 15 & $\mathrm{a}, \mathrm{b}$ & $\mathrm{a}: \mathrm{c} 1, \mathrm{~s} 2 ; \mathrm{b}: \mathrm{s} 1, \mathrm{~s} 2$ & 8.5 & 10 \\
25.5 & 0.8127 & 191.7663 & 15 & $\mathrm{a}, \mathrm{b}$ & $\mathrm{a}: \mathrm{s} 1$ & 5.5 & 6 \\
\hline
\end{tabular}

model at each altitude (see Fig. 3, Table 1) reveals that the indicator function has the largest signal and smallest relative uncertainty at $17.5 \mathrm{~km}$. This test points to an artificial step between OSIRIS and SAGE II time series, likely due to an imprecise anomaly bias correction, which likely stems partly from the seasonal biases in OSIRIS. Thus, we present the trend above $18 \mathrm{~km}$, where the indicator function signal is weaker and the linear trends (SAGE II, OSIRIS, merged) are consistent within the uncertainty of the merged trend.

In order to validate our linear trends, we can compare our linear trend profile using only SAGE II data with that determined by Forster et al. (2007) and Randel and Wu (2007) for a very similar latitude band. At $18.5 \mathrm{~km}$, their decadal trends are $\sim-7.5$ and $\sim-5.7 \%$ respectively. The magnitude of our SAGE II linear trend (1984-2005) at $18.5 \mathrm{~km}$ is $(-3.3 \pm 4.8) \%$ decade $^{-1}$. Our $95 \% \mathrm{CI}$ is very large here since the SAGE II time series is shorter and sparser than the merged one. At $19.5 \mathrm{~km}$, Forster et al. (2007) and Randel and $\mathrm{Wu}$ (2007) show decadal trends of $\sim-6.5 \%$ and $\sim-3.8 \%$, and we find $(-3.9 \pm 4.0) \%$ decade $^{-1}$, in closer agreement with Randel and $\mathrm{Wu}$ (2007). There is consistency on the shape of our SAGE II trend profile in the 18.5-25.5 km range (Fig. 4) with these recent studies.

Figure 4 also shows the trends from OSIRIS, which are highly uncertain (i.e. $95 \%$ CIs are larger than the trend) due to the short data record, except at $25.5 \mathrm{~km}$.

The 95\% CIs on the linear trend for the merged data set are comparable to the variability in the linear trend due to the choice of model terms, indicating that wisely choosing these explanatory variables can clearly reduce the overall error budget on the linear trend. However, at $25.5 \mathrm{~km}$, ozone variability is explained almost entirely by the QBO as its signal is an order of magnitude stronger than that from any other predictor (Fig. 3), and thus the linear trend is not sensitive to the other regression model terms. The linear trend for the merged data set is not sensitive to the QBO pair because of the short period of its cycles. At each altitude, the best estimate of the linear trend for the merged data set falls within the range of linear trends predicted by applicable best models developed for other altitudes (see Fig. 4 caption), providing confidence in the method. The merging of OSIRIS and SAGE II data sets yields much smaller linear trend uncertainties than SAGE II alone. The merging allows for the detection of a statistically significant trend at $18.5-24.5 \mathrm{~km}$, not found with SAGE II alone (except at $21.5-22.5 \mathrm{~km}$ ). The linear trends from the SAGE II and OSIRIS data sets are in agreement at all altitudes, except at $24.5-25.5 \mathrm{~km}$, where the OSIRIS trend values are positively biased (Fig. 4). The general agreement is expected if the linear trend in ozone has not changed in the last three decades. Figure 4 shows our best estimate for the decadal trend (1984-2012) at $18.5 \mathrm{~km}$ is $-6.5 \%$ (95\% CI: -8.4 to $-4.7 \%)$. Comparing with the only other linear-trend study in the tropical lower stratosphere using SAGE II merged with more recent data, Randel and Thompson (2011) found statistically significant negative trends between 18 and $22.5 \mathrm{~km}$ (but not statistically significant at 23 to $24.5 \mathrm{~km}$ ) in a $20^{\circ} \mathrm{N}-20^{\circ} \mathrm{S}$ band in the 1984 to 2009 period using SAGE II plus ozonesondes. Our results are quite similar to those of Randel and Thompson (2011), with a statistically significant negative trend (1984-2009) in the 17.5 to $24.5 \mathrm{~km}$ range but not statistically significant at $25.5 \mathrm{~km}$ (Fig. 4). The magnitude of our merged trend (19842012) is only larger than theirs in a statistically significant way at $22.5-24.5 \mathrm{~km}$, whereas our SAGE II trend (19842005) is not larger in magnitude than their (merged) trend at any altitude.

Next, we discuss the ozone variations attributable to various predictors and revisit the sensitivity of the solar term to the final linear trend estimate in Fig. 4.

\subsection{ENSO}

After deseasonalizing the ozone data records, the important predictors of ozone variability throughout the tropical lower stratosphere (LS) are QBO, ENSO, tropopause pressure, and the linear trend, which are all statistically significant 
at all altitudes in the $18.5-24.5 \mathrm{~km}$ range (Fig. 3), and only tropopause pressure and the linear trend are not statistically significant at $25.5 \mathrm{~km}$. At $18.5 \mathrm{~km}$, the ozone response to ENSO is $(-5.8 \pm 4.2) \%$, a value that agrees very well with a previous estimate (Randel and Thompson, 2011). ENSO explains almost as much of the variance as the QBO at $18.5 \mathrm{~km}$ and more than the linear term in the $18.5-21.5 \mathrm{~km}$ range. The major La Niña events of 1988-1989 and 1999-2000 (Randel and Thompson, 2011) appear as positive ozone anomalies in Fig. 5b, and the latter one was also observed by HALOE (Solomon et al., 2012). The lag, much like the amplitude of ENSO, is increasingly important at the tropopause $(17.5 \mathrm{~km})$, where a half-month error can reduce both the unexplained portion of the ozone variance and the linear trend uncertainty by $\sim 1 \%$ (relative), whereas above $19 \mathrm{~km}$, the $r^{2}$ reduction is never $>0.35 \%$.

Figure 3 shows that the fitted amplitudes of ENSO, tropopause pressure and the linear trend all peak at $18.5 \mathrm{~km}$. They decrease strongly with increasing altitude, whereas the amplitude of the QBO signal in ozone, which peaks at $19.5 \mathrm{~km}$, only decreases by $30 \%$ up to $25.5 \mathrm{~km}$. ENSO and tropopause pressure signals exponentially decay with scale heights of $\sim 4 \mathrm{~km}$. This is expected since the QBO is a lowerto middle-stratospheric phenomenon with strong zonal wind velocities at $10 \mathrm{hPa}$, whereas ENSO, in essence, is a disturbance to the Walker circulation in the troposphere (and related ocean temperature and dynamical changes). The expected altitude dependence of the response of ozone to linear and tropopause terms is discussed in Sect. 4.1.

\subsection{QBO}

In the $18-26 \mathrm{~km}$ range, QBO is the key predictor of ozone variability (see Fig. 5d,f). The response to QBO is consistent with Randel and Thompson (2011) if one accounts for the different widths of our respective latitude bands. The best single QBO pressure at an altitude (as defined in Sect. 2.2) tends to correspond approximately to the pressure at that altitude (see Table 1). For example, at $17.5 \mathrm{~km}(\sim 85 \mathrm{hPa})$, the best single pressure is naturally $70 \mathrm{hPa}$, with $30 \mathrm{hPa}$ being a nearly orthogonal complement. A QBO time series at $90 \mathrm{hPa}$ might be useful but is not available except for the radiosonde station at Singapore. The complementary QBO term between 21.5 and $23.5 \mathrm{~km}$ tends to be at a lower pressure and is orthogonal to the QBO time series at the local pressure. Above $22 \mathrm{~km}$, there is also a tendency for the best single QBO pressure to be slightly lower than the local pressure (i.e. higher altitude). These tendencies toward lower pressures likely arise from the shape of the age of air spectrum being more skewed to older air with increasing altitude (National Aeronautics and Space Administration, 1999). The "orthogonal" complementary QBO pressures tend to have a lag of one-fourth of the QBO period relative to the best single QBO pressure and thus provide maximum independent information and also account for any lag in the ozone re-
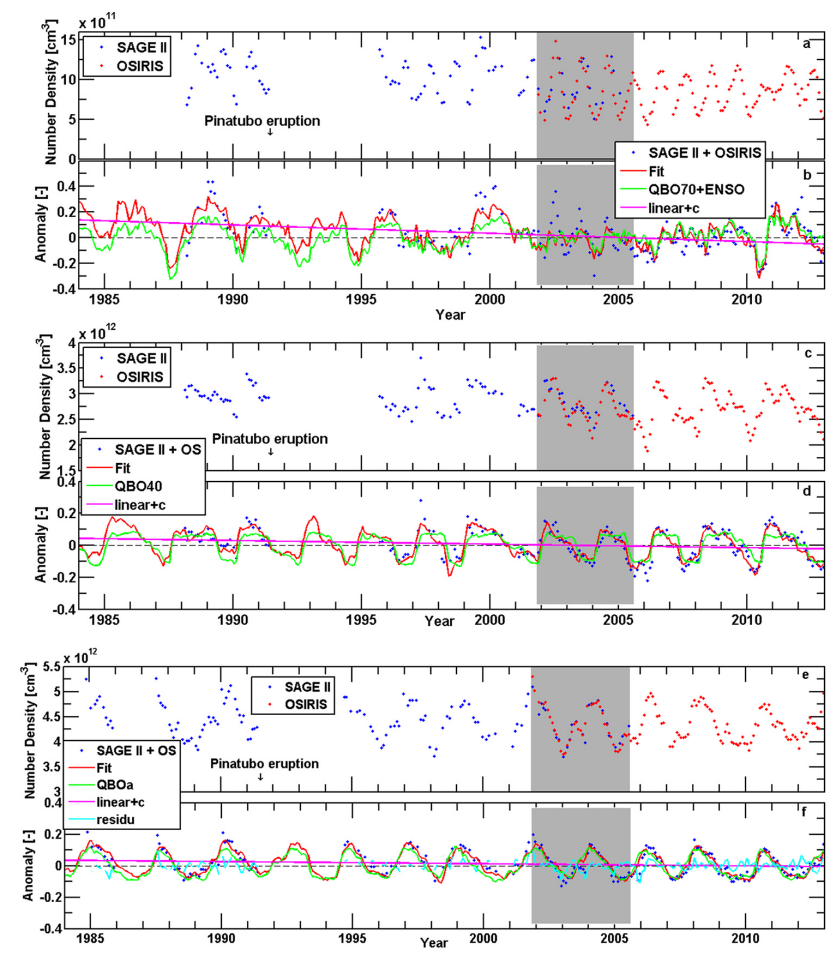

Fig. 5. This figure consists of three two-panel plots. The upper panel in each shows the ozone number density time series from SAGE II and OSIRIS ("OS") separately. The overlap period is shaded grey. Note that these are the original data (no inter-instrument bias removed). The lower panel in each plot is the merged ozone anomaly time series (blue dots). The red line represents the fit provided by the regression model to this time series. The green line shows the ozone response of the dominant predictor (predictors) which correlates (correlate) with the dependent variable to $>0.5$. The three altitudes shown from top to bottom are $18.5,21.5$, and $24.5 \mathrm{~km}$. The ozone data have been filtered at the start of the SAGE II record as described in Sect. 2.1.1, most extensively at $22.5 \mathrm{~km}$ and below, because of the residual aerosol layer from El Chichón (peak altitude of $19.5 \mathrm{~km}$ in 1985), which erupted in April 1982, and then Nevado del Ruiz, which erupted on 13 November 1985 (Yue et al., 1991) and whose peak altitude was $22.5 \mathrm{~km}$ in early 1987 . The eruption of Mt. Pinatubo, which occurred in June 1991, is marked in the upper panels.

sponse to the local QBO signal (Witte et al., 2008). These pairs of QBO basis functions act similarly to the orthogonalized QBO basis functions of Randel and Wu (2007). In fact, the correlation between 10 and $30 \mathrm{hPa}$, and between 30 and $70 \mathrm{hPa}$ is weaker than the correlation between the two orthogonalized QBO basis functions. Figure $5 \mathrm{~d}$ and $\mathrm{f}$ also illustrate that the QBO signature is altitude-dependent and any attempt to fit the QBO signal with time series at a single inappropriate pressure (even with a lag) (e.g. Cunnold et al., 2000; Bodeker et al., 2013) will fail to capture the altitude dependence of the QBO signal. For example, the QBO signal in ozone exhibits sharp temporal changes at the times of extreme amplitude at $24.5 \mathrm{~km}$, whereas at $21.5 \mathrm{~km}$ it has 
much more of a square-wave character (see also Dunkerton and Delisi, 1985). This is particularly evident during the two QBO cycles in the 1998 to 2003 time frame. This finding extends beyond ozone to understanding variations of other applicable trace gases (e.g. water vapour). Thus, it is not surprising that in the $17.5-23.5 \mathrm{~km}$ range, fitting the best pair of pressures considerably improves the $r^{2}$ relative to fitting two orthogonalized QBO basis functions (Randel and Wu, 2007) derived from all seven pressures, as echoed by Kirgis et al. (2013). In fact, in some cases, a single QBO pressure (e.g. $50 \mathrm{hPa}$ at $19.5 \mathrm{~km}$ ) explains much more variance than the two orthogonalized QBO basis functions. This method of accounting for the altitude dependence of the QBO in vertically resolved ozone time series analysis allows for $r^{2}=0.74$ using only SAGE II data at $18.5 \mathrm{~km}$ in contrast to $\leq 0.4$ found by Randel and $\mathrm{Wu}$ (2007) (see also Table 1 for altitude dependence of $r^{2}$ using the merged data set) and improves the linear trend uncertainty. However, at higher altitudes (24.5$25.5 \mathrm{~km}$ ), the use of orthogonalized QBO basis functions (Randel and Wu, 2007) considerably improves the fit of the regression over any pair of QBO pressures. This is expected since air at $24-26 \mathrm{~km}$ has a much broader range of ages than air below $21 \mathrm{~km}$ (which has highly peaked age spectrum and is thus represented well by the QBO signature at a single appropriate pressure or two enveloping pressure levels). Given the possible correlation of time series at adjacent QBO pressures, which occurs at $19.5 \mathrm{~km}$ (Table 1), where the best pair is 50 and $70 \mathrm{hPa}$ and the correlation coefficient between these QBO time series is 0.64 , we verified using an alternate, more orthogonal pair (30 and $70 \mathrm{hPa}$ ) that there is no statistically significant change in the magnitude of the linear trend but a larger linear trend uncertainty using the latter QBO pair. The semi-annual harmonic of the QBO is a weaker signal than the annual one as expected for the tropical LS (Dunkerton, 1990).

\subsection{Tropopause pressure}

We are able to detect a coherent tropopause pressure signal in the ozone anomaly time series that increases with decreasing height and decays exponentially up to $25.5 \mathrm{~km}$ (Fig. 3). The linear trend magnitude does not change in a statistically significant way with tropopause pressure included in the final regression model at any altitude; however the trend uncertainty profile is reduced considerably.

\subsection{Solar variability}

The solar cycle term does not appear in the best regression model for altitudes in the $17.5-24.5 \mathrm{~km}$ range, in spite of the merged data set spanning nearly three solar cycles. Between 17.5 and $20.5 \mathrm{~km}$, including the solar term worsens the linear trend uncertainty and biases the linear trend, although the magnitude of the solar fitting coefficient is larger than its $95 \%$ CI. For all of the other predictors, if their fit- ting coefficient was larger than its $95 \% \mathrm{CI}$, the inclusion of that predictor tended to improve the linear trend uncertainty as well. The special behaviour of the solar term relates to its number of cycles in the merged data record being small and a non-integer. Our trend-oriented stepwise regression modelling is different from regression models targeting an overall understanding of sources of variability (e.g. Randel and $\mathrm{Wu}$, 2007). We also find anomalous solar signals below $21 \mathrm{~km}$ if we duplicate their method. A positive ozone response arises $(+0.4 \%)$ at $25.5 \mathrm{~km}$ which is not significant after autocorrelation is taken into account.

\section{Discussion}

Regarding the autocorrelation of the merged data set given our choice of a monthly time step, we find that there is no obvious altitude dependence to the autocorrelation, except for higher autocorrelation at $18.5 \mathrm{~km}(\varphi=0.777)$, whereas the other altitudes are in the $\varphi=0.56 \pm 0.05$ range for AR1. For a 2-month lag, $\varphi$ is less than 0.32 at all altitudes, except again at $18.5 \mathrm{~km}$. If the inter-sensor bias between SAGE II and OSIRIS at $18.5 \mathrm{~km}$ is not equal to the bias during the overlap period (e.g. due to instrument degradation), a high autocorrelation will result in the merged data set. At $18.5 \mathrm{~km}$, the merged data set has a much higher AR1 autocorrelation than for the individual SAGE II and OSIRIS data sets (0.26 and 0.65 , respectively). The autocorrelation in the merged data set is not much larger than in the individual data sets at higher altitudes. Above $18.5 \mathrm{~km}$, the autocorrelation in the merged data set tracks the autocorrelation in the OSIRIS data set because, despite its currently shorter time span than SAGE II, OSIRIS already has more monthly samples in this latitude band. The autocorrelation statistics suggest that a 2-month sampling increment should be considered in future work.

\subsection{Comparison of observed and calculated trend profiles}

In the following section, we present a simple formula for calculating the trend profile and use available information from a modelling study, as well as NCEP reanalysis data and satellite-based observations of the vertical gradient of ozone to quantify the trend. The zonal average continuity equation for ozone mixing ratio is written as (Andrews et al., 1987)

$\frac{\partial \bar{x}}{\partial t}=\nabla \cdot M+P-L-\bar{v} \bar{x}_{y}-\bar{w} \bar{x}_{z}$,

where $\bar{x}$ is the zonally averaged ozone mixing ratio; $\nabla \cdot M$ is the eddy transport; $P$ and $L$ are chemical production and loss; $\bar{v}$ and $\bar{w}$ are the meridional and vertical flow velocities; and $\bar{x}_{y}$ and $\bar{x}_{z}$ denote the meridional and vertical ozone gradients, where, for example, the latter gradient can be written explicitly as $\partial \bar{x} / \partial z$. The linear trend in local production is expected to be positive in the tropical LS over the 1984-2012 period (Lamarque and Solomon, 2010); therefore this term 
cannot explain the sign of the observed ozone trend. Ray et al. (2010) included trends in in-mixing in their model and the resulting ozone trend does not correctly produce the sign or shape of the observed trend in the $20^{\circ} \mathrm{N}-20^{\circ} \mathrm{S}$ band (Randel and Thompson, 2011). Clearly more modelling work is needed in this area, but this is outside of the scope of this paper. Thus we focus on the final term in Eq. (8). The final term is thought to be responsible for the ozone trend since the relative trend in $\bar{w}$ has been modelled and is consistent in sign and relative magnitude with the ozone anomaly trend (Lamarque and Solomon, 2010). The continuity equation as written in Eq. (8) is appropriate for any instant in time, but the vertical velocity and the vertical mixing ratio gradient are a function of time; therefore we write these factors as $\bar{w}(t)$ and $\bar{x}_{z}(t)$ and their trends are written as $\partial \bar{w} / \partial t$ and $\partial \bar{x}_{z} / \partial t$. Analogous to Randel et al. (2007), if we divide the continuity equation by the long-term zonal average mixing ratio $(\bar{x})$ to obtain an ozone fractional difference continuity equation, the vertical gradient term is given by $\partial \ln (\bar{x}) / \partial z$ and is a local maximum at $18 \pm 0.5 \mathrm{~km}$ according to OSIRIS and SAGE II with profiles that are very similar in shape and magnitude to those obtained with SHADOZ ozonesondes data (Randel et al., 2007). Peak values are 0.68 and $0.84 \ln (\mathrm{ppm}) / \mathrm{km}$ for OSIRIS and SAGE II, respectively. First, we provide support that the trend terms $\partial \bar{w} / \partial t$ and $\partial \bar{x}_{z} / \partial t$ are different than zero.

According to model simulations by Lamarque and Solomon (2010), the trend in the vertical velocity $(\partial \bar{w} / \partial t)$ at $85 \mathrm{hPa}$ over the period $1970-2005$ is $\sim 0.23 \pm 0.02 \mathrm{~km} /$ year $/$ decade (or $\sim 4 \% \mathrm{decade}^{-1}$ ) considering all forcings (including a variety of greenhouse gases), whereas the trend due to $\mathrm{CO}_{2}$ and sea surface temperature increases is $0.17 \mathrm{kmyear}^{-1} \mathrm{decade}^{-1}$, and the trend due to halocarbons is only $0.05 \mathrm{~km}$ year $^{-1} \mathrm{decade}^{-1}$. Thus the trend in tropical upwelling in the tropical LS is primarily due to $\mathrm{CO}_{2}$ (as sea surface temperature rise is strongly driven by increases in atmospheric $\mathrm{CO}_{2}$ but with a lag due to the thermal inertia of the oceans) (e.g. Bryan et al., 1982). The tropical upwelling continues to increase with height throughout the LS (Lamarque and Solomon, 2010), but the temporal trend in tropical upwelling $(\partial \bar{w} / \partial t)$ is largest (in units of km year ${ }^{-1}$ decade $^{-1}$ ) at $17.5 \mathrm{~km}$ based on multiplying the relative trend profile by the vertical velocity profile (both panels of Fig. 1 of Lamarque and Solomon, 2010).

The trend in the vertical gradient of ozone mixing ratio $\left(\partial \bar{x}_{z} / \partial t\right)$ in the tropical LS is largely determined by the trend in tropopause pressure. The sensitivity of ozone mixing ratio to tropopause pressure $\left(\partial \bar{x} / \partial p_{\text {trop }}\right)$ at various altitudes can be determined by a simple linear regression assuming that the sensitivity of ozone to tropopause pressure changes is not a function of the timescale of the tropopause pressure variations. SAGE II and OSIRIS ozone mixing ratios correlate very well $\left(r^{2}>0.5\right)$ with tropopause pressure in the $16.5-19.5 \mathrm{~km}$ but not well outside this narrow range. An overall range of 14.5 to $25.5 \mathrm{~km}$ was studied. At $17.5 \mathrm{~km}$, $r^{2}$ values are 0.8058 and 0.6921 for the fit of SAGE II and OSIRIS mixing ratios, respectively, to tropopause pressure plus a constant. Thus, we use the equation

$\frac{\partial \bar{x}_{z}}{\partial t}=\frac{d\left(\frac{\partial \bar{x}}{\partial p_{\text {trop }}} \frac{\partial p_{\text {trop }}}{\partial t}\right)}{\partial z}$

and take the value of the second factor in the numerator on the right-hand side of the above from the caption of Fig. 2. The first factor is obtained from the simple linear regression and then the product is numerically differentiated with respect to height. At the tropopause, we find that a -3.5 and $-4.4 \%$ decadal trend in ozone is expected from the linear trend in tropopause pressure using SAGE II and OSIRIS, respectively, to determine vertical gradient in ozone.

The relative ozone trend $\left(\%\right.$ decade $\left.^{-1}\right)$ can be determined by differentiating the final term on the right-hand side of Eq. (8):

$$
\frac{\partial \bar{x}}{\bar{x} \partial t}=\frac{\left(\bar{w}+\frac{\partial \bar{w}}{\partial t} \partial t\right)\left(\bar{x}_{z}+\frac{\partial \bar{x}_{z}}{\partial t} \partial t\right)-\bar{w} \bar{x}_{z}}{\bar{w} \bar{x}_{z} \partial t}=\frac{\left(\bar{x}_{z} \frac{\partial \bar{w}}{\partial t}+\bar{w} \frac{\partial \bar{x}_{z}}{\partial t}\right)}{\bar{w} \bar{x}_{z}},
$$

where $\partial \bar{x}_{z} / \partial t$ is replaced by Eq. (9) and a minor term is neglected which involves the product of both time derivatives in Eq. (10). In summary, the $\partial \bar{x}_{z} / \partial t$ peaks at $18 \pm 0.5 \mathrm{~km}$ in both satellite data sets and $\partial \bar{w} / \partial t$ peaks in the troposphere, whereas $\bar{w}$ and $\bar{x}_{z}$ peak above $25 \mathrm{~km}$. Also, note that trends due to the other terms in Eq. (8) have not been included.

Using either satellite data set for $\bar{x}_{z}$, the first trend component $\left(\bar{x}_{z} \partial \bar{w} / \partial t\right)$ in Eq. (10) gradually increases with increasing height in the tropical LS. The second theoretical trend component $\left(\bar{w} \bar{\partial}^{2} x_{z} / \partial t\right)$ also shows a peak near the tropopause ( $17 \pm 0.5 \mathrm{~km}$ in both data sets). After summing these two theoretical trend terms, the trend in ozone mixing ratio (in ppm decade ${ }^{-1}$ ) peaks at $18 \pm 0.5 \mathrm{~km}$ (using both data sets). Converting to a relative trend (i.e. an anomaly) amplifies the peak and shifts it downward to $16.5 \mathrm{~km}$ (using either data set). Note also that the relative vertical velocity trend profile $\partial \ln (\bar{w}) / \partial t$ peaks at $17.5 \mathrm{~km}$, whereas the trend in the vertical gradient of fractional ozone $\partial \ln (\bar{w}) / \partial t$ increases down to the lowest altitude used in computing trends $(15.5 \mathrm{~km})$. The computed magnitude of the negative trend in ozone reaches a maximum at $16.5 \mathrm{~km}$ of $10.25 \pm 0.05 \%$, where the uncertainty is the difference between trends computed using SAGE II and OSIRIS vertical gradients. Figure 6 shows the agreement between the observed trend from the merged data set and the calculated trend using either SAGE II or OSIRIS to determine the vertical gradient of ozone. Also illustrated is the dominant contribution to the ozone trend from the trend in tropical upwelling (the first trend term), which can be inferred by differencing the calculated trend including both trend terms and the calculated trend from only the second term of rightmost part of Eq. (10). Note that the tropical upwelling and its temporal trend were obtained from Lamarque and Solomon (2010) and are appropriate for a wider latitude 
band $\left(20^{\circ} \mathrm{N}-20^{\circ} \mathrm{S}\right)$ as well as a different time period (19752005) and that vertical gradients from OSIRIS and SAGE II are naturally for shorter time periods than the observed merged trend.

Equation (10) indicates that the relative trend in ozone is equal to the relative trend in tropical upwelling if vertical gradient trends are neglected. Comparing the ozone trend in Lamarque and Solomon (2010) (their Fig. 2, right panel) for the "all forcings" case and their vertical velocity trend (their Fig. 1, right panel), one can see that the magnitude of the tropical upwelling trend is essentially equal to the magnitude of the ozone trend except at the tropopause, where the ozone trend goes to 0 but the vertical velocity trend is $2 \%$ decade $^{-1}$.

One weakness of our simple trend model is that, as well as being a function of latitude, altitude, and time, $\bar{w}$ and $\bar{x}_{z}$ may be functions of each other, which would complicate the calculus of Eq. (10). In statistical terms, this interdependence is measured by correlation. In atmospheric physics terms, this could be considered coupling or a feedback which could be positive or negative and varying with altitude. The correlation between $\bar{w}$ and $\bar{x}_{z}$ is weak $(r=-0.1$ on a $1 \mathrm{~km}$ grid between 15.5 and $24.5 \mathrm{~km}$ with the aforementioned data sources). However, the correlation appears to be stronger at the tropopause, where trends in the vertical gradient of ozone can lead to trends in the vertical gradient of temperature since ozone is involved in atmospheric heating and affects the temperature profile. In turn, this could affect the trend in tropical upwelling. Conversely, the vertical gradient of ozone could also be a function of the tropical upwelling. In any case, Fig. 6 illustrates good agreement in the ozone trend profile determined with this simple model with no feedbacks and the merged observational data set.

It is clear that $\mathrm{CO}_{2}$ has been increasing steadily for decades and ozone in the tropical LS has been decreasing linearly, but in order to demonstrate that the positive trend in $\mathrm{CO}_{2}$ is driving the negative linear trend in ozone in the tropical LS, we establish here that increases in $\mathrm{CO}_{2}$ appear to lead to linear trends in both tropical upwelling (Butchart et al., 2010) and tropopause pressure (Lamarque and Solomon, 2010). Recall that the tropopause pressure trend directly relates to the trend in the vertical gradient of ozone, which is the second physical mechanism responsible for ozone trends based on Eq. (10). Butchart et al. (2010) show that the tropical upwelling trend due to increases in greenhouse gases is expected to be linear over 140 years (1960-2100). Regarding the tropopause pressure trend, the linearity can be inferred from the small uncertainty of the linear trend coefficient when using a simple linear regression of time to the tropopause pressure (Lamarque and Solomon, 2010). The linear trend on tropopause pressure is statistically significant within $\pm 10^{\circ}$ of the Equator (Lamarque and Solomon, 2010). If the tropopause pressure were changing in a non-linear way as a result of increases in $\mathrm{CO}_{2}$ (and sea surface temperature), the trend would not be significant using a simple linear regression. Also, the NCEP tropopause pressure linear trend

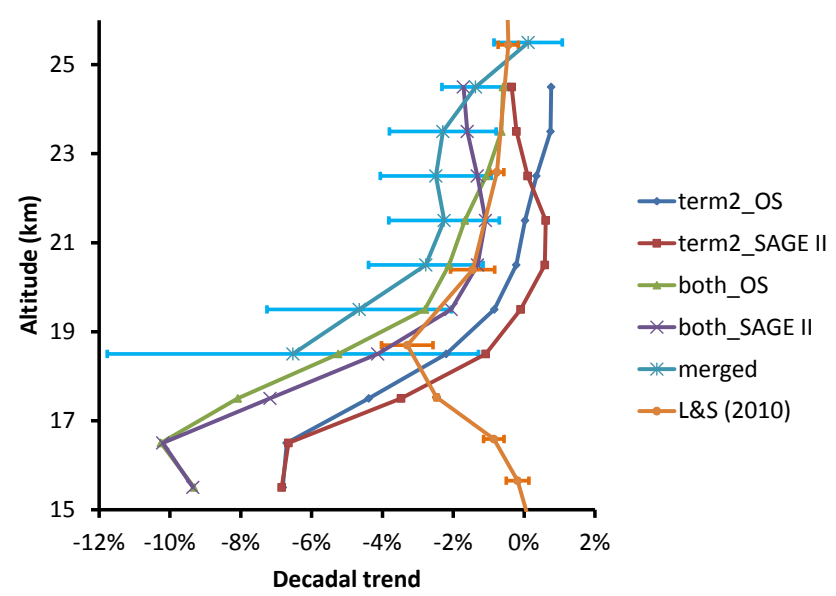

Fig. 6. Observed and calculated ozone trends for 1984-2005. The observed trend is labelled "merged" and is the trend shown in Fig. 4 for the merged data set. The trend profiles labelled "both_OS" and "both_SAGE II" are calculated trends including contributions from the trend in tropical upwelling and the trend in the vertical gradient of ozone, with the vertical gradient of ozone supplied by either OSIRIS or SAGE II. The profiles labelled term 2 consider only the contribution from the trend in the vertical gradient of ozone (see Sect. 4.1 for details). L\&S (2010) is the model simulations of Lamarque and Solomon (2010) for $1979-2005$ and $20^{\circ} \mathrm{S}-20^{\circ} \mathrm{N}$.

is also statistically significant within $10^{\circ}$ of the Equator and agrees very well with the linear trend in tropopause pressure from a model simulation in which only $\mathrm{CO}_{2}$ and sea surface temperature increases are considered and a second model simulation in which all forcings are considered. For the latter simulation $\left(20^{\circ} \mathrm{N}-20^{\circ} \mathrm{S}\right)$, the linear trend uncertainty in tropopause pressure is $<20 \%$ and is expected to be smaller for a narrower latitude band centred on the Equator.

\subsection{Non-linear sources of variability}

At $17.5-18.5 \mathrm{~km}$, the seasonal variations in ozone number density are very large yet can vary from year to year (Fig. 5a). This is particularly obvious when looking at the OSIRIS time frame where there are fewer data gaps and comparing the strong annual cycles of 2002-2004 to subsequent years. Variance of this sort is difficult to remove by deseasonalization or by regression modelling (Fig. 5b) even if a seasonal trend had been included. Understanding what controls the year-to-year variability of the seasonal cycle (Ploeger et al., 2012; Witte et al., 2008) could lead to an improved regression model and have an impact on estimated trends and their uncertainties. It is doubtful that annual harmonics of QBO, ENSO, or the solar cycle could explain the strong annual cycles of the overlap period immediately above the tropopause, although the combined effect of annual QBO and ENSO harmonics should be investigated when an improved version of the OSIRIS ozone retrieval becomes available. Note that there is good 
agreement on the magnitude of the seasonal cycle between the two instruments during the overlap period (Fig. 5a).

Using SAGE II data only, we found that the harmonic of the linear trend (seasonal trend) and the same harmonic of a constant (seasonal cycle) are never statistically significant predictors with the same sign at any altitude (even when using a best regression model specifically for SAGE II at $18.5 \mathrm{~km}$ ). This means that there is no evidence supporting a seasonal trend. This is important given the approach taken in the deseasonalization of the data using the seasonal cycle from the full data record (of each instrument). Also, when testing the seasonal trend term with the merged data set, its amplitude was found to be weak ( $<3 \%$ ozone response), and simply acted to capture any residual seasonality in the ozone anomalies from subtle changes in the phase of the seasonal cycle between instruments.

As discussed above, optimizing the ENSO lag can improve fitting, particularly near the tropopause $(17.5 \mathrm{~km})$. Using an altitude-independent lag of 2 months (Randel and Thompson, 2011) is adequate in the lowermost stratosphere $(z<21 \mathrm{~km})$, where the ENSO signal is strongest. Chemistry and transport models show that air at any location has a variety of ages due to transport. The frequency distribution of ages is called an age spectrum, and its central tendency can be measured using the mode. We expect the observed ENSO lag profile (Table 1) to correspond to modal age of air, and indeed it compares well with other estimates in the tropical pipe (e.g. Strahan et al., 2009). Information on the mode of the age of air is important for modelling transport pathways such as horizontal mixing. The modal age of air (relative to the time of stratospheric entry) is also available observationally from the transit period obtained from tape recorder plots. The noise level on the ENSO lag signal in ozone appears to be $\sim 0.5$ month below $22 \mathrm{~km}$, whereas above $22 \mathrm{~km}$, the lag signal becomes increasingly less reliable for the latitude band of $0 \pm 4.5^{\circ}$. Using a narrower latitude band $\left(0 \pm 2.5^{\circ}\right)$, the ENSO lag signal appears more reliably up to $24.5 \mathrm{~km}$. With either latitude band, we obtain a modal age of air at $23.5 \mathrm{~km}$ of 9 months from the ENSO lag signal in the ozone time series in quantitative agreement with the transit period method.

\section{Conclusions}

We have shown that anomaly biases between OSIRIS and SAGE II in the overlap period (2001-2005) are small $(<2 \%)$ when each data set is deseasonalized separately.

This study has demonstrated that a merged satellite data set, such as this one which spans 28 continuous years, is not limited simply by random sources of error in the measurements even as low as $18.5 \mathrm{~km}$ but also by phenomena such as year-to-year seasonal cycle amplitude variations and subtle biases between the two independent data sets in the phase of seasonal cycle. The difficulty in fully capturing the interannual variation of the seasonal amplitude in the 2002-2004 time frame could affect the trend determined for the OSIRIS time period (2001-2012) and, to a lesser extent, the trend in the merged data set.

The linear trend is a statistically significant basis function at all altitudes in the $18.5-24.5 \mathrm{~km}$ range, and statistically insignificant at $25.5 \mathrm{~km}$ over the merged time period. Extending the ozone record by merging SAGE II and OSIRIS data allows for a significant reduction in trend uncertainties relative to those from SAGE II alone at all altitudes, except at $18.5 \mathrm{~km}$. EESC is not statistically significant at any of these altitudes (see Fig. 3 as well as Sect. 2.2). Our results are consistent with model results showing that the driving forces behind the decadal changes in ozone in the tropical LS are increases in greenhouse gases and sea surface temperature (Lamarque and Solomon, 2010), which affect tropical upwelling and the vertical gradient of ozone. Thus, in the absence of any new, dominant mechanism, decreasing ozone in the tropical LS can be expected for at least the current century according to model simulations (Waugh et al., 2009).

Merging other satellite data sets with SAGE II might also be a valuable exercise given the reduction in trend uncertainty by merging OSIRIS and SAGE II. Future trend modelling should also include new versions of the OSIRIS ozone product with a focus on trying to use merged data sets to obtain trend information with reduced uncertainties at 17.5 or $16.5 \mathrm{~km}$ which could be used to confirm our understanding of the involved physical mechanisms.

Acknowledgements. We thank L. Rieger (University of Saskatchewan) for help with the SAGE II data and F. Wu (National Center for Atmospheric Research, NCAR) for providing us with empirical orthogonal functions for modelling the quasibiennial oscillation and the observed trend profile from Randel and Thompson (2011). We acknowledge B. Randel (NCAR) for suggesting the idea of sensor-specific deseasonalization. We thank N. Lloyd for comments regarding OSIRIS data and acknowledge his effort in processing OSIRIS level 0 and 1 data. We acknowledge funding from the Canadian Space Agency.

Edited by: M. Dameris

\section{References}

Adams, C., Bourassa, A. E., Bathgate, A. F., McLinden, C. A., Lloyd, N. D., Roth, C. Z., Llewellyn, E. J., Zawodny, J. M., Flittner, D. E., Manney, G. L., Daffer, W. H., and Degenstein, D. A.: Characterization of Odin-OSIRIS ozone profiles with the SAGE II dataset, Atmos. Meas. Tech., 6, 1447-1459, doi:10.5194/amt6-1447-2013, 2013.

Adams, C., Bourassa, A. E., Sofieva, V., Froidevaux, L., McLinden, C. A., Hubert, D., Lambert, J.-C., Sioris, C. E., and Degenstein, D. A.: Assessment of Odin-OSIRIS ozone measurements from 2001 to the present using MLS, GOMOS, and ozonesondes, Atmos. Meas. Tech., 7, 49-64, doi:10.5194/amt-7-49-2014, 2014. 
Andrews, D. G., Holton, J. R., and Leovy, C. B.: Middle Atmosphere Dynamics, International Geophysical Series, Vol. 40, Academic Press, 489 pp., 1987.

Baldwin, M. P., Gray, L. J., Dunkerton, T. J., Hamilton, K., Haynes, P. H., Randel, W. J., Holton, J. R., Alexander, M. J., Hirota, I., Horinouchi, T., Jones, D. B. A., Kinnersley, J. S., Marquardt, C., Sato, K., and Takahashi, M.: The Quasi-biennial oscillation, Rev. Geophys., 39, 179-229, 2001.

Bodeker, G. E., Boyd, I. S., and Matthews, W. A.: Trends and variability in vertical ozone and temperature profiles measured by ozonesondes at Lauder, New Zealand: 1986-1996, J. Geophys. Res., 103, 28661-28681, 1998.

Bodeker, G. E., Hassler, B., Young, P. J., and Portmann, R. W.: A vertically resolved, global, gap-free ozone database for assessing or constraining global climate model simulations, Earth Syst. Sci. Data, 5, 31-43, doi:10.5194/essd-5-31-2013, 2013.

Bourassa, A. E., Rieger, L. A., Lloyd, N. D., and Degenstein, D. A.: Odin-OSIRIS stratospheric aerosol data product and SAGE III intercomparison, Atmos. Chem. Phys., 12, 605-614, doi:10.5194/acp-12-605-2012, 2012.

Bovensmann, H., Burrows, J. P., Buchwitz, M., Frerick, J., Noël, S., and Rozanov, V. V.: SCIAMACHY: Mission objectives and measurement modes, J. Atmos. Sci., 56, 127-150, 1999.

Brohede, S., Jones, A., and Jégou, F.: Internal consistency in the Odin stratospheric ozone products, Can. J. Phys., 85, 1275-1285, 2007.

Bryan, K., Komro, F. G., Manabe, S., and Spelman, M. J.: Transient climate response to increasing atmospheric carbon dioxide, Science, 215, 56-58, 1982.

Bunzel, F. and Schmidt, H.: The Brewer-Dobson circulation in a changing climate: Impact of the model configuration, J. Atmos. Sci., 70, 1437-1455, 2013.

Butchart, N., Cionni, I., Eyring, V., Shepherd, T., Waugh, D., Akiyoshi, H., Austin, J., Brühl, C., Chipperfield, M., Cordero, E., Dameris, M., Deckert, R., Dhomse, S., Frith, S., Garcia, R., Gettelman, A., Giorgetta, M., Kinnison, D., Li, F., Mancini, E., McLandress, C., Pawson, S., Pitari, G., Plummer, D., Rozanov, E., Sassi, F., Scinocca, J., Shibata, K., Steil, B., and Tian, W.: Chemistry-climate model simulations of 21 st century stratospheric climate and circulation changes, J. Climate, 23, 53495374, doi:10.1175/2010JCLI3404.1, 2010.

Chu, W. P., McCormick, M. P., Lenoble, J., Brogniez, C., and Pruvost, P.: SAGE II Inversion Algorithm, J. Geophys. Res., 94, 8339-8351, 1989.

Cooper, M., Martin, R. V., Sauvage, B., Boone, C. D., Walker, K. A., Bernath, P. F., McLinden, C. A., Degenstein, D. A., Volz-Thomas, A., and Wespes, C.: Evaluation of ACE-FTS and OSIRIS Satellite retrievals of ozone and nitric acid in the tropical upper troposphere: Application to ozone production efficiency, J. Geophys. Res., 116, D12306, doi:10.1029/2010JD015056, 2011.

Cunnold, D. M., Wang, H. J., Thomason, L. W., Zawodny, J. M., Logan, J. A., and Megretskaia, I. A.: SAGE (version 5.96) ozone trends in the lower stratosphere, J. Geophys. Res., 105, 44454457, 2000.

Damadeo, R. P., Zawodny, J. M., Thomason, L. W., and Iyer, N.: SAGE version 7.0 algorithm: application to SAGE II, Atmos. Meas. Tech., 6, 3539-3561, doi:10.5194/amt-6-3539-2013, 2013.
Degenstein, D. A., Bourassa, A. E., Roth, C. Z., and Llewellyn, E. J.: Limb scatter ozone retrieval from 10 to $60 \mathrm{~km}$ using a multiplicative algebraic reconstruction technique, Atmos. Chem. Phys., 9, 6521-6529, doi:10.5194/acp-9-6521-2009, 2009.

Dunkerton, T. J.: Annual variation of deseasonalized mean flow acceleration in the equatorial lower stratosphere, J. Meteorol. Soc. Jpn., 68, 499-508, 1990.

Dunkerton, T. J. and Delisi, D. P.: Climatology of the equatorial lower stratosphere, J. Atmos. Sci., 42, 376-396, 1985.

Dupuy, E., Walker, K. A., Kar, J., Boone, C. D., McElroy, C. T., Bernath, P. F., Drummond, J. R., Skelton, R., McLeod, S. D., Hughes, R. C., Nowlan, C. R., Dufour, D. G., Zou, J., Nichitiu, F., Strong, K., Baron, P., Bevilacqua, R. M., Blumenstock, T., Bodeker, G. E., Borsdorff, T., Bourassa, A. E., Bovensmann, H., Boyd, I. S., Bracher, A., Brogniez, C., Burrows, J. P., Catoire, V., Ceccherini, S., Chabrillat, S., Christensen, T., Coffey, M. T., Cortesi, U., Davies, J., De Clercq, C., Degenstein, D. A., De Mazière, M., Demoulin, P., Dodion, J., Firanski, B., Fischer, H., Forbes, G., Froidevaux, L., Fussen, D., Gerard, P., GodinBeekmann, S., Goutail, F., Granville, J., Griffith, D., Haley, C. S., Hannigan, J. W., Höpfner, M., Jin, J. J., Jones, A., Jones, N. B., Jucks, K., Kagawa, A., Kasai, Y., Kerzenmacher, T. E., Kleinböhl, A., Klekociuk, A. R., Kramer, I., Küllmann, H., Kuttippurath, J., Kyrölä, E., Lambert, J.-C., Livesey, N. J., Llewellyn, E. J., Lloyd, N. D., Mahieu, E., Manney, G. L., Marshall, B. T., McConnell, J. C., McCormick, M. P., McDermid, I. S., McHugh, M., McLinden, C. A., Mellqvist, J., Mizutani, K., Murayama, Y., Murtagh, D. P., Oelhaf, H., Parrish, A., Petelina, S. V., Piccolo, C., Pommereau, J.-P., Randall, C. E., Robert, C., Roth, C., Schneider, M., Senten, C., Steck, T., Strandberg, A., Strawbridge, K. B., Sussmann, R., Swart, D. P. J., Tarasick, D. W., Taylor, J. R., Tétard, C., Thomason, L. W., Thompson, A. M., Tully, M. B., Urban, J., Vanhellemont, F., Vigouroux, C., von Clarmann, T., von der Gathen, P., von Savigny, C., Waters, J. W., Witte, J. C., Wolff, M., and Zawodny, J. M.: Validation of ozone measurements from the Atmospheric Chemistry Experiment (ACE), Atmos. Chem. Phys., 9, 287-343, doi:10.5194/acp-9-287-2009, 2009.

Fioletov, V. E.: Ozone climatology, trends, and substances that control ozone, Atmos. Ocean, 46, 39-67, 2008.

Flittner, D. E., Bhartia, P. K., and Herman, B. M.: $\mathrm{O}_{3}$ profiles retrieved from limb scatter measurements: Theory, Geophys. Res. Lett., 27, 2601-2604, 2000.

Forster, P. M., Bodeker, G., Schofield, R., Solomon, S., and Thompson, D.: Effects of ozone cooling in the tropical lower stratosphere and upper troposphere, Geophys. Res. Lett., 34, L23813, doi:10.1029/2007GL031994, 2007.

Haley, C. S., Brohede, S. M., Sioris, C. E., Griffioen, E., Murtagh, D. P., McDade, I. C., Eriksson, P., Llewellyn, E. J., Bazureau, A., and Goutail, F.: Retrieval of stratospheric $\mathrm{O}_{3}$ and $\mathrm{NO}_{2}$ profiles from Odin Optical Spectrograph and Infrared Imager System (OSIRIS) limb-scattered sunlight measurements, J. Geophys. Res., 109, D16303, doi:10.1029/2004JD004588, 2004.

Hassler, B., Bodeker, G. E., and Dameris, M.: Technical Note: A new global database of trace gases and aerosols from multiple sources of high vertical resolution measurements, Atmos. Chem. Phys., 8, 5403-5421, doi:10.5194/acp-8-5403-2008, 2008.

Hood, L. L., Soukharev, B. E., and McCormack, J. P.: Decadal variability of the tropical stratosphere: Secondary influence of the 
El Niño-Southern Oscillation, J. Geophys. Res., 115, D11113, doi:10.1029/2009JD012291, 2010.

Jones, A., Urban, J., Murtagh, D. P., Eriksson, P., Brohede, S., Haley, C., Degenstein, D., Bourassa, A., von Savigny, C., Sonkaew, T., Rozanov, A., Bovensmann, H., and Burrows, J.: Evolution of stratospheric ozone and water vapour time series studied with satellite measurements, Atmos. Chem. Phys., 9, 6055-6075, doi:10.5194/acp-9-6055-2009, 2009.

Kalnay E., Kanamitsu, M., Kistler, R., Collins, W., Deaven, D., Gandin, L., Iredell, M., Saha, S., White, G., Woollen, J., Zhu, Y., Chelliah, M., Ebisuzaki, W., Higgins, W., Janowiak, J., Mo, K. C., Ropelewski, C., Wang, J., Leetmaa, A., Reynolds, R., Jenne, R., and Joseph, D.: The NCEP/NCAR 40-year reanalysis project, B. Am. Meteorol. Soc., 77, 437-470, 1996.

Kirgis, G., Leblanc, T., McDermid, I. S., and Walsh, T. D.: Stratospheric ozone interannual variability (1995-2011) as observed by lidar and satellite at Mauna Loa Observatory, HI and Table Mountain Facility, CA, Atmos. Chem. Phys., 13, 5033-5047, doi:10.5194/acp-13-5033-2013, 2013.

Konopka, P., Grooß, J.-U., Günther, G., Ploeger, F., Pommrich, R., Müller, R., and Livesey, N.: Annual cycle of ozone at and above the tropical tropopause: observations versus simulations with the Chemical Lagrangian Model of the Stratosphere (CLaMS), Atmos. Chem. Phys., 10, 121-132, doi:10.5194/acp-10-121-2010, 2010.

Lamarque, J.-F. and Solomon, S.: Impact of changes in climate and halocarbons on recent lower stratosphere ozone and temperature trends, J. Climate, 23, 2599-2611, 2010.

Llewellyn, E. J., Lloyd, N. D., Degenstein, D. A., Gattinger, R. L., Petelina, S. V, Bourassa, A. E., Wiensz, J. T., Ivanov, E. V, McDade, I. C., Solheim, B. H., McConnell, J. C., Haley, C. S., Von Savigny, C., Sioris, C. E., McLinden, C. A., Griffioen, E., Kaminski, J., Evans, W. F. J., Puckrin, E., Strong, K., Wehrle, V., Hum, R. H., Kendall, D. J. W., Matsushita, J., Murtagh, D. P., Brohede, S., Stegman, J., Witt, G., Barnes, G., Payne, W. F., Piché, L., Smith, K., Warshaw, G., Deslauniers, D., Marchand, P., Richardson, E. H., King, R. A., Wevers, I., McCreath, W., Kyrölä, E., Oikarinen, L., Leppelmeier, G. W., Auvinen, H., Mégie, G., Hauchecorne, A., Lefèvre, F., de La Nöe, J., Ricaud, P., Frisk, U., Sjoberg, F., Von Schéele, F., and Nordh, L.: The OSIRIS instrument on the Odin spacecraft, Can. J. Phys., 82, 411-422, doi:10.1139/P04-005, 2004.

McLinden, C. A., Bourassa, A. E., Brohede, S., Cooper, M., Degenstein, D. A., Evans, W. F. J., Gattinger, R. L., Haley, C. S., Llewellyn, E. J., Lloyd, N. D., Loewen, P., Martin, R. V., McConnell, J. C., McDade, I. C., Murtagh, D., Rieger, L., von Savigny, C., Sheese, P. E., Sioris, C. E., Solheim, B., and Strong, K.: OSIRIS: a decade of scattered light, B. Am. Meteorol. Soc., 93, 1845-1863, 2012.

National Aeronautics and Space Administration, Models and measurements intercomparison II, Ed. NASA/TM-1999-209554, Hampton, VA, 493 pp., 1999.

Naujokat, B.: An update of the observed quasi-biennial oscillation of the stratospheric winds over the tropics, J. Atmos. Sci., 43, 1873-1877, 1986.

Newman, P. A., Daniel, J. S., Waugh, D. W., and Nash, E. R.: A new formulation of equivalent effective stratospheric chlorine (EESC), Atmos. Chem. Phys., 7, 4537-4552, doi:10.5194/acp7-4537-2007, 2007.
Ploeger, F., Konopka, P., Müller, R., Fueglistaler, S., Schmidt, T., Manners, J. C., Grooß, J.-U., Günther, G., Forster, P. M., and Riese, M.: Horizontal transport affecting trace gas seasonality in the Tropical Tropopause Layer (TTL), J. Geophys. Res., 117, D09303, doi:10.1029/2011JD017267, 2012.

Randel, W. J. and Thompson, A. M.: Interannual variability and trends in tropical ozone derived from SAGE II satellite data and SHADOZ ozonesondes, J. Geophys. Res., 116, D07303, doi:10.1029/2010JD015195, 2011.

Randel, W. J. and Wu, F.: A stratospheric ozone profile data set for 1979-2005: Variability, trends, and comparisons with column ozone data, J. Geophys. Res., 112, D06313, doi:10.1029/2006JD007339, 2007.

Randel, W. J., Park, M., Wu, F., and Livesey, N.: A large annual cycle in ozone above the tropical tropopause linked to the BrewerDobson circulation, J. Atmos. Sci., 64, 4479-4488, 2007.

Randel, W. J., Garcia, R. R., Calvo, N., and Marsh, D.: ENSO influence on zonal mean temperature and ozone in the tropical lower stratosphere, Geophys. Res. Lett., 36, L15822, doi:10.1029/2009GL039343, 2009.

Ray, E. A., Holton, J., R., Fishbein, E. F., Froideveaux, L., and Waters, J. W.: The tropical semiannual oscillations in temperature and ozone as observed by the MLS, J. Atmos. Sci., 51, 30453052, 1994.

Ray, E. A., Moore, F. L., Rosenlof, K. H., Davis, S. M., Boenisch, H., Morgenstern, O., Smale, D., Rozanov, E., Hegglin, M., Pitari, G., Mancini, E., Braesicke, P., Butchart, N., Hardiman, S., Li, F., Shibata, K., and Plummer, D. A.: Evidence for changes in stratospheric transport and mixing over the past three decades based on multiple data sets and tropical leaky pipe analysis, J. Geophys. Res., 115, D21304, doi:10.1029/2010JD014206, 2010.

Reinsel, G. C., Tiao, G. C., DeLuisi, J. J., Mateer, C. L., Miller, A. J., and Frederick, J. E.: Analysis of upper stratospheric Umkehr ozone profile data for trends and the effects of stratospheric aerosols, J. Geophys. Res., 89, 4833-4840, 1984.

Rusch, D. W. and Clancy, R. T.: A comparison of ozone trends from SME and SBUV satellite observations and model calculations, Geophys. Res. Lett., 15, 776-779, 1988.

Schubert, S. D. and Munteanu, M.-J.: An analysis of tropopause pressure and total ozone correlations, Mon. Weather Rev., 116, 569-582, 1988.

Solomon, S., Young, P. J., and Hassler, B.: Uncertainties in the evolution of stratospheric ozone and implications for recent temperature changes in the tropical lower stratosphere, Geophys. Res. Lett., 39, L17706, doi:10.1029/2012GL052723, 2012.

Strahan, S. E., Schoeberl, M. R., and Steenrod, S. D.: The impact of tropical recirculation on polar composition, Atmos. Chem. Phys., 9, 2471-2480, doi:10.5194/acp-9-2471-2009, 2009.

von Savigny, C., Haley, C. S., Sioris, C. E., McDade, I. C., Llewellyn, E. J., Degenstein, D., Evans, W. F. J., Gattinger, R. L., Griffioen, E., Kyrölä, E., Lloyd, N. D., McConnell, J. C., McLinden, C. A., Mégie, G., Murtagh, D. P., Solheim, B., and Strong, K.: Stratospheric ozone profiles retrieved from limb scattered sunlight radiance spectra measured by the OSIRIS instrument on the Odin satellite, Geophys. Res. Lett., 30, 1755, doi:10.1029/2002GL016401, 2003.

Wallace, J. M., Panetta, R. L., and Estberg, J.: Representation of the equatorial stratospheric quasi-biennial oscillation in EOS phase space, J. Atmos. Sci., 50, 1751-1762, 1993. 
Wang, H. J., Cunnold, D. M., Thomason, L. W., Zawodny, J. M., and Bodeker, G. E.: Assessment of SAGE version 6.1 ozone data quality, J. Geophys. Res., 107, 4691, doi:10.1029/2002JD002418, 2002.

Waugh, D. W., Oman, L., Kawa, S. R., Stolarski, R. S., Pawson, S., Douglass, A. R., Newman, P. A., and Nielsen, J. E.: Impacts of climate change on stratospheric ozone recovery, Geophys. Res. Lett., 36, L03805, doi:10.1029/2008GL036223, 2009.

Witte, J. C., Schoeberl, M. R., Douglass, A. R., and Thompson, A. M.: The Quasi-biennial Oscillation and annual variations in tropical ozone from SHADOZ and HALOE, Atmos. Chem. Phys., 8, 3929-3936, doi:10.5194/acp-8-3929-2008, 2008.

WMO: The Stratosphere 1981; Theory and measurements. WMO Global ozone research and monitoring project - Report No. 11, Geneva, Switzerland, 514 pp., 1982.

WMO: Report of the international ozone trends panel: 1988. Global ozone research and monitoring project - Report No. 18, Geneva, Switzerland, 829 pp., 1990.

WMO: SPARC/IOC/GAW assessment of trends in the vertical distribution of ozone, Global ozone research and monitoring project - Report No. 43, 1998.
WMO: Scientific Assessment of Ozone Depletion: 1998, Global ozone research and monitoring project - Report No. 44, Geneva, Switzerland, 1999.

WMO: Scientific Assessment of Ozone Depletion: 2002, Global ozone research and monitoring project - Report No. 47, Geneva, Switzerland, 498 pp., 2003.

WMO: Scientific assessment of ozone depletion: 2006. Global ozone research and monitoring project - Report No. 50, Geneva, Switzerland, 572 pp., 2007.

WMO: Scientific assessment of ozone depletion: 2010. Global ozone research and monitoring project - Report No. 52, Geneva, Switzerland, 516 pp., 2011.

Wolter, K.: Multivariate ENSO Index (MEI), available at: www.esrl. noaa.gov/psd/enso/mei/table.html (last access: 10 May 2013), 2013.

Yue, G. K., McCormick, M. P., and Chiou, E. W.: Stratospheric aerosol optical depth observed by the Stratospheric Aerosol and Gas Experiment II: Decay of the El Chichon and Ruiz Volcanic Perturbations, J. Geophys. Res., 96, 5209-5219, 1991. 